\title{
Cationic Dynamic Covalent Polymers for Gene Transfection
}

Received 00th January 20xx, Accepted 00th January 20xx

DOI: $10.1039 / \times 0 \times x 00000 x$

\author{
Dandan Su, ${ }^{\mathrm{a}, \mathrm{b}}$ Maëva Coste, ${ }^{\mathrm{b}}$ Andrei Diaconu, ${ }^{\mathrm{c}}$ Mihail Barboiu, ${ }^{\mathrm{a} *}$ Sébastien Ulrich ${ }^{\mathrm{b} *}$
}

\section{Introduction}

Genetic disorders caused by mutations of genes and chemical damages to DNA or RNA form a large set of diseases, including many cancers, neurofibromatosis, muscular dystrophies, Parkinson disease, etc. ${ }^{1}$ There is therefore a great interest in manipulating with precision nucleic acids (i.e. replacing, correcting, inserting, deleting). A number of nucleic acids have emerged as potential drugs such as pDNA for "Gene Therapy", siRNA for "Silencing Therapy", 2 mRNA, up to the now-famous gene editing tools that include CRISPR-Cas9. However, nucleic acids cannot enter cells without help, which makes this delivery issue a central challenge in the field of gene therapies. Therefore, the big question regarding the translation of these nucleic acids into real drugs is: how to effectively and safely deliver nucleic acids to fix genetic malfunctions?

At present, viruses are most often used as vectors because they still are most effective. However, they also pose serious safety concerns due to their immunogenicity/genotoxicity, ${ }^{3}$ not to mention their high cost of production and their narrow range of application with respect to the type of nucleic acid they can carry and the cell types onto which delivery is effective. Artificial alternatives are therefore much desired but despite decades of work they still remain elusive as an universal, safe and cheap solution to this big challenge. Generally, non-viral vectors are synthetic materials, based on amphiphilic cationic lipids, ${ }^{4}$ cationic polymers, ${ }^{5,6-8}$ and their subsequent assemblies into micelles, liposomes etc, that can

\footnotetext{
Institut Européen des Membranes, Adaptive Supramolecular Nanosystems Group, University of Montpellier, ENSCM, CNRS, Place Eugène Bataillon, CC 047, F34095, Montpellier, France. Email: mihail-dumitru.barboiu@umontpellier.fr b. Institut des Biomolécules Max Mousseron (IBMM), CNRS, Université of Montpellier, ENSCM, Montpellier, France.Email: sebastien.ulrich@enscm.fr c.Petru Poni" Institute of Macromolecular Chemistry of Romanian Academy, 41A, Aleea Gr. Ghica Voda, Iasi, Romania.
}

electrostatically recognize nucleic acids and transport them into cellular environment. $6,7,9,10$ For instance, Lipofectamine ${ }^{\circledR}$ is a commercially-available cationic lipid that is nowadays commonly used in laboratories around the world, yet, like many other applications in the clinic is still hampered by its toxicity. ${ }^{11}$ Meanwhile, cationic polymers came out thanks to their ease of preparation, accessible structural diversity and good ability to condense nucleic acids. ${ }^{12}$ Rapid progresses in cationic polymers provided safer systems for effective nucleic acid transfection, although still failing for translation to the clinic because of toxicity issues. ${ }^{11,12}$ Dynamic Combinatorial Chemistry (DCC $)^{13-19}$ enables access to large chemical libraries starting from molecular building blocks that reversibly interact with each other through reversible covalent reactions. ${ }^{20,21,22}$ This means that dynamic covalent systems, formed through multiple reversible covalent bonds, can adapt their structure in response to physico-chemical stimuli. ${ }^{23-27}$ Over the last decade, DCC has led to the development of Dynamic Covalent Polymers (DCP) which have attracted a great interest in the material chemistry community for their self-healing and adaptive properties. ${ }^{28-35}$ Currently, there is also a greater interest in the potential of such dynamic materials for nucleic acid delivery, motivated by the alluring possibilities to identify more effective vectors through dynamic combinatorial screening where building blocks compete and only the best fitted DCP binder is expressed when the target of choice is present. The ability to adaptively control the spatial distribution of interchangeable recognition groups on the dynamic surfaces of such reversible materials, may induce a high level of correlativity of synergetic interaction with the nucleic acid and the membrane barrier. In other words, this leaves the nucleic acid to template and to self-generate the fittest DCP material, for its own compaction. While this may represent a universal approach to identifying gene delivery vectors, it also bears the advantage of producing vectors self- 
fitted for one particular application through a versatile approach that should be low cost compared to the production of viral vectors. In this review, we aim to highlight recent advances of cationic dynamic covalent polymers in gene transfection that have developed prospective gene delivery systems. Significant examples will be summarised, involving different architectures of synthetic dynamic polymers including dynamic cationic amphiphiles, linear dynamic polymers, side-chain dynamic polymers and dynamic threedimensional frameworks.

\section{Design of Dynamic Covalent Polymers for gene transfection}

\subsection{Structural and functional considerations}

Polymers are macromolecular assemblies of monomers. They vary in length, polydispersity, composition, linkage, sequences, as well as in their capacity to further self-assemble into higherorder assemblies (e.g. micelles, polymersomes). These parameters are of utmost importance as they dictate their binding efficacy, binding selectivity, cell penetration, as well as their toxicity toward transfected cells. Gene delivery is a complex multi-step process involving i) nucleic acid complexation, ii) nanoparticle formation, iii) (targeted) diffusion/transport in tissues, iv) (targeted) cellular uptake, v) endosomal escape, and vi) nucleic acid release (Fig. 1). ${ }^{36}$ Important criteria must therefore be fulfilled for the successful development of effective non-viral vectors, and their integration within a single system remains a current challenge. ${ }^{6,37-40}$ For instance, extracellular transport requires synthetic carriers to protect genes from degradation by nucleolytic enzymes and to form nanoparticles with good serum stability and targetability. ${ }^{41}$ As for intracellular barriers, polymeric carriers must own functionalities for endosomal escape, nuclear transport in case of pDNA delivery, and nucleic acid release. ${ }^{42}$ The need for effective nucleic acid complexation and release, seemingly conflicting, is a daunting challenge for classical polymers which has prompted the development of degradable polymers ${ }^{43-45}$ and self-assembling low-molecularweight dendrimers ${ }^{46-50}$ that release nucleic acids upon degradation/dissociation. ${ }^{47-60}$ Similarly, dynamic covalent polymers have a strong advantage in terms of responsiveness that enables to manipulate, through dynamic covalent exchange reactions, multivalent binding to nucleic acids for achieving nucleic acid complexation and release. ${ }^{21,61}$ On top of that and quite uniquely, dynamic covalent polymers are capable of adaptation, meaning they can adapt their length, composition, and sequences to environmental conditions (e.g. $\mathrm{pH}$, redox) and/or to the presence of a interacting biomolecular target (e.g. nucleic acid, cell membrane).

Numerous cationic polymers have been reported, ${ }^{62}$ but despite a better understanding ${ }^{63-65}$ it often remains very hard to establish clear structure-activity relationships and the large differences in biological activity commonly observed call for great care when designing the molecular components of polymer vectors. ${ }^{66,67}$ Recent advances have been made using

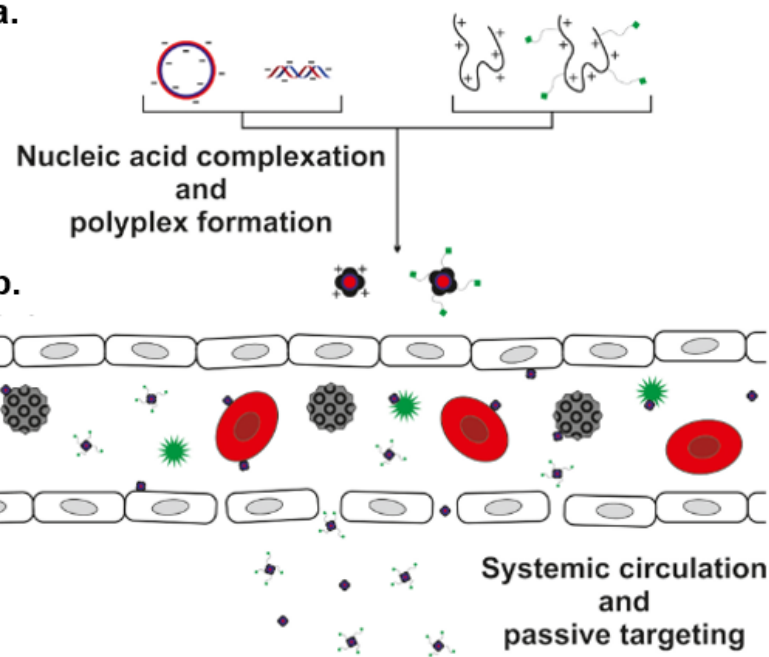

c.

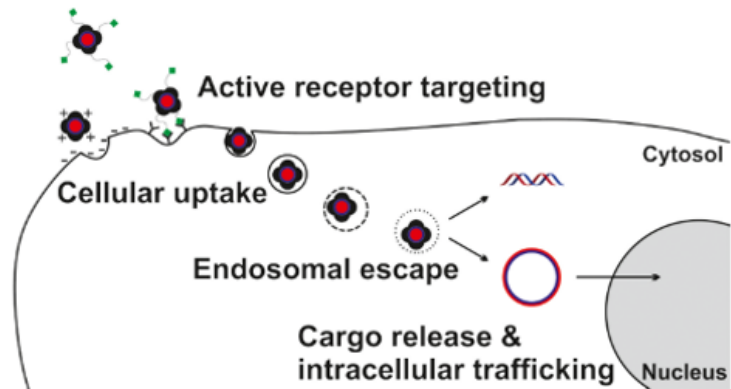

Fig. 1 Barriers in the nucleic acid delivery pathway of polyplexes. ${ }^{36}$ a) nucleic acids complexation, b) systemic circulation of polyplexes in blood, and c) cellular barriers encountered by polyplexes during cell internalisation. Reproduced with permission from ref. 36. Copyright 2015 American Chemical Society.

degradable linkers and co-polymers that feature multiple groups involved in nucleic acid complexation, cell penetration, and endosomal escape (Fig. 2a). ${ }^{45,68}$ However, since an ideal design is impossible to achieve a priori through a rational approach, robot-assisted combinatorial screening with automated polyplex preparation can be implemented in multiple-well plate formats in order to decipher structural aspects and find better and safer polymer vectors for gene transfection (Fig. 2b). ${ }^{69,70}$ Although costly, this approach enables a more rapid screening of different types of polymers on different cell types based on a range of criteria such as complex size determination, DNA binding affinity, polyplex stability, cytotoxicity, and transfection efficiency using optical assays. As an alternative exploiting reversible covalent chemistry, DCC offers the advantage that polymers do not need to be pre-assembled but it is precisely the binding to nucleic acids and/or the transport of the polyplex inside cells that amplify the formation of the best suited polymer vector from a pool of competing monomers. While such an approach has already been successful in medicinal chemistry programs, ${ }^{71}$ it is true that its implementation in delivery applications remains more challenging. However, the recent demonstration by Alfonso et al. of DCC carried out on live cells represents a milestone achievement in this direction. ${ }^{72}$ In a DCC approach, the dynamic platforms result by (molecular/supramolecular) self-assembly of specific core-connectors with the constitutive segments or the functional bio-interacting sites. The reversibility of the interactions between the components may 


\section{a. Rational Design of Cationic Polymers}

$$
\text { ancis }
$$

Degradable polymers

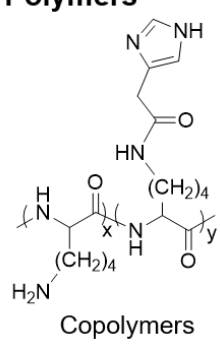

\section{b. Parallel High-Throughput (HT) Screening of Polymer Vectors}

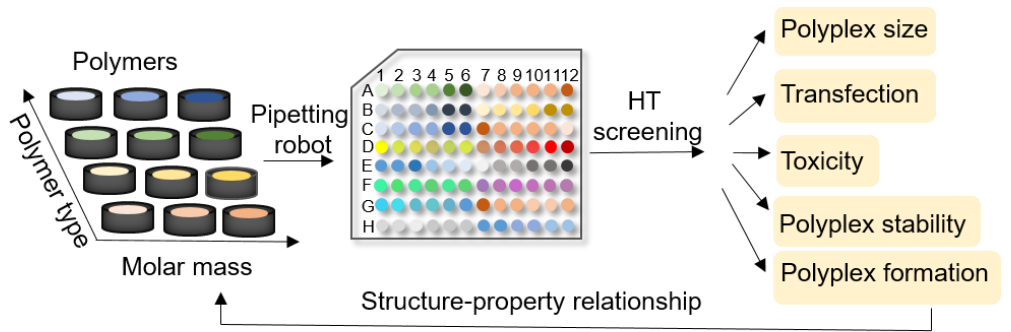

c. Dynamic Combinatorial Transfectors

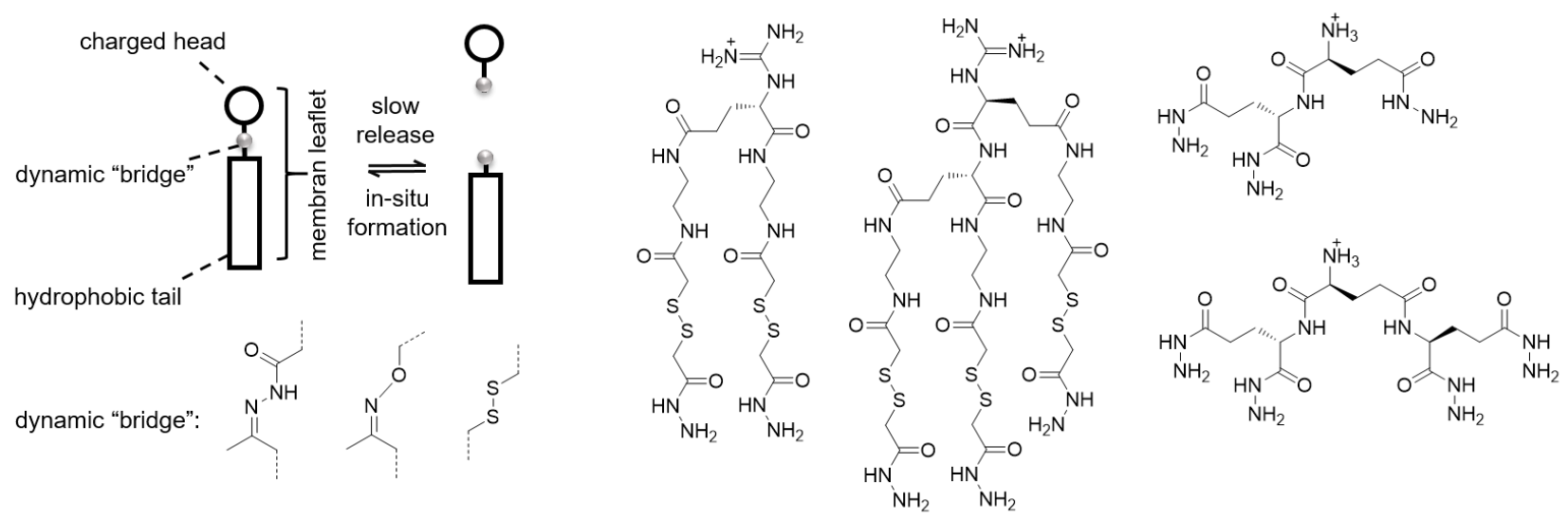

\section{d. Dynamic Covalent Polymers}

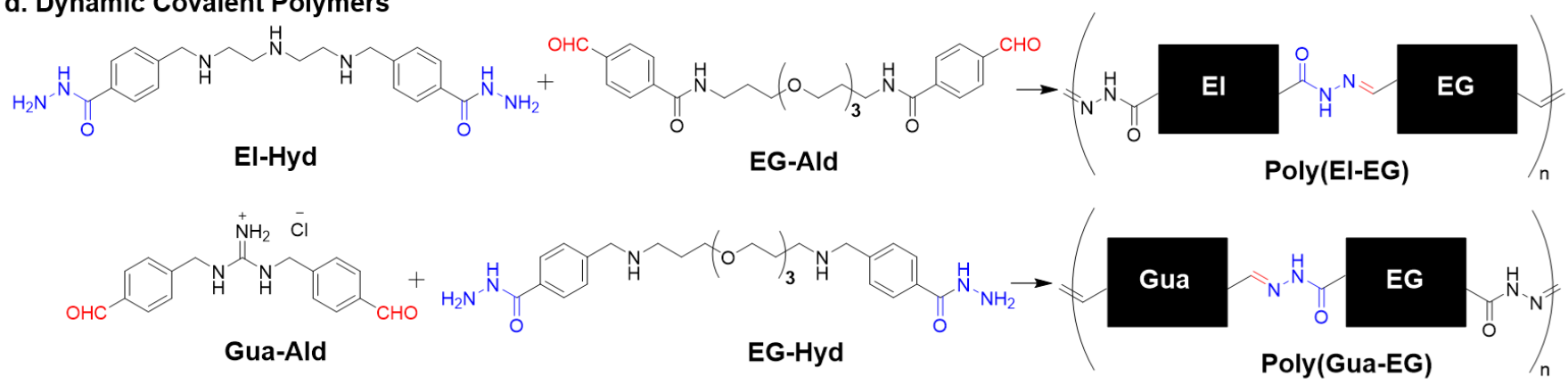

\section{e. Dynamic Constitutional Frameworks}

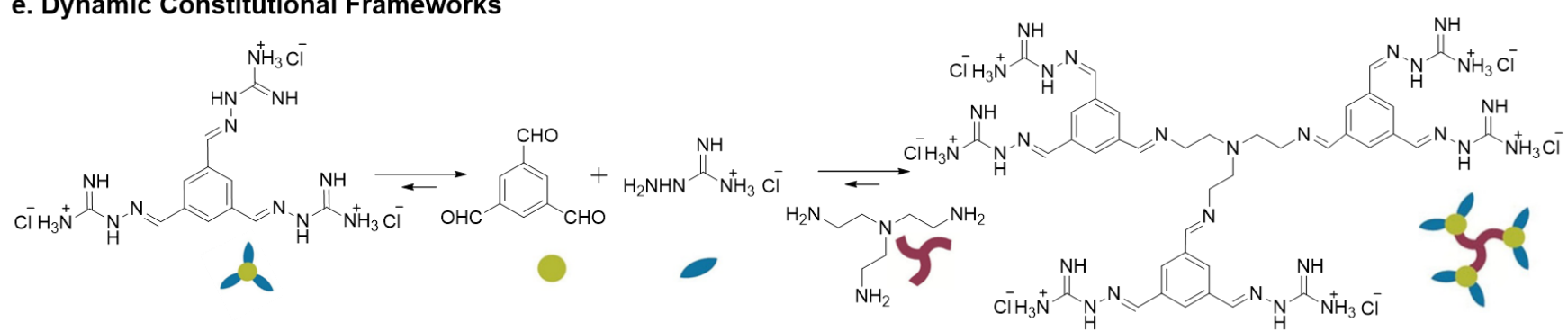

Fig. 2 Strategies for identifying polymer vectors for gene delivery: a) rational design of degradable and multifunctional block copolymers, b) high-throughput combinatorial screening, c) dynamic combinatorial transfectors based on cationic amphiphiles, d) dynamic covalent polymers, and e) 3D dynamic constitutional frameworks.

finely and adaptively mutate the positioning of the components in the chemical space, resulting in the selfformation of the most adapted platform in the presence of DNA target and bilayer cell membrane environment. ${ }^{73,74}$ Intricate dynamic configuration can provide much more active molecular, supramolecular or polymeric assemblies, making it possible to adapt an optimal structure for gene delivery at different dimensional levels. This emerging approach has hitherto been explored on three different systems: i) dynamic amphiphilic transfectors (Fig. 2c), ${ }^{75}$ dynamic covalent polymers
(Fig. 2d), ${ }^{76}$ and dynamic constitutional frameworks (Fig. 2e) $)^{77}$ which will be discussed in more details in this review.

\subsection{Design criteria for positively-charged molecular building blocks}

Cationic binding groups promote nucleic acid complexation via electrostatic interaction with the phosphodiester groups, which results in charge compensation and thus triggers a subsequent condensation into a nanoparticle ${ }^{78}$ protected from enzymatic degradation. ${ }^{36}$ However, cytotoxicity and rapid hemolysis is also related to cationic density such that great care must be taken when selecting the nature and number of 


Compound

Table 1 Representative positively-charged compounds commonly inserted in cationic polymers for gene delivery

cationic groups to be inserted within the polymer vector. ${ }^{79,80}$ Common cationic compounds, including polyethyleneimine, 81,82 guanidinium ${ }^{83}$ and amino acids 84,85 have been used for the construction of cationic polymers (Table 1).

As a typical cationic polymer, branched polyethyleneimine (PEI), having a series of primary, secondary and tertiary amines groups, displays favourable electrostatic adsorption to DNA, and shows buffer ability that promote endosomal escape. ${ }^{81,86,87}$ Their divergent synthesis enables tuning the number and density of branching points, and varying the ratio between the three different types of amine. ${ }^{81,88} \mathrm{~A}$ wide range of molecular weights, highly positive charges, topological structures and hydrophilic ability of PEIs, are critical facets that influence the transfection efficiency as well as the blood circulation time. ${ }^{89,90}$ Different studies have proved that higher molecule weight PEI ( $\geq 25 \mathrm{kDa}$ ) are effective gene delivery vectors but could lead to undesirable cytotoxic effects caused by aggregation behaviours, while smaller molecular weight PEI ( $\leq 2000 \mathrm{Da}$ ) could exhibit limited transfection efficiency. ${ }^{91,92}$

Guanidinium cations are very strong binders of negativelycharged oxoanions due to their high pKa $(\approx 13)$ which make them permanently protonated in biological media. The introduction of cationic guanidinium groups can be achieved by guanidinylation ${ }^{93,94}$ or by using off-the-shelf arginine as a guanidinium-containing amino-acids. ${ }^{67,95}$ Arginine-containing compounds interact very well, via salt-bridge interactions, with the phosphodiesters of nucleic acids - an effect which has been coined "arginine magic". ${ }^{96,97}$ The length, number and density of positive charges are key factors when using oligoarginine conjugates in gene delivery. ${ }^{98}$ Some artificial derivatives of guanidiniums such as the guanidiniocarbonyl pyrrole motif show improved oxoanion binding and thus bears a strong potential for nucleic acid delivery applications. ${ }^{99-101}$ Histidine also can be grafted to cationic polymers. Thanks to the low pKa of its imidazole ring( $\approx 6)$, it often partake in an acid-dependent fusion and leakage of liposomes. ${ }^{102}$ The high loading of histidine into cationic polymers effectively promote efficient endosomal escape but can also sometimes be deleterious to the nucleic acid complexation - the benefit to the overall transfection efficiency being affected by the casedependent relative importance of those two steps. ${ }^{103-105}$ In contrast, although lysine-containing cationic polymers are better at nucleic acid complexation and cell penetration, ${ }^{106,107}$ they do not display effective endosomolytic activity, thereby causing low transfection efficiency. ${ }^{104,108}$

\subsection{Reversible reactions suitable in gene delivery applications}

Dynamic constitutional chemistry rests on reversible covalent reactions. Various reversible reactions, such as amino/carbonyl-imines, sulphides/disulphides, Diels-Alder reaction, alkene and alkyne metathesis, have been applied to design dynamic covalent polymers as adaptive functional materials. ${ }^{13,61,109-115}$ The reversibility of dynamic linkages endow polymers with attractive functionality, for example selfhealing, stimulus-responsiveness, degradability, recyclability and replasticity. Despite such prominent developments of DCPs in the field of material science, the application in gene delivery is a much more recent adventure which bears distinct challenges. For instance, considering the unique conditions that exist in biological environments, adjustment and rearrangement of reversible linkages must be compatible with an aqueous medium and must operate at room temperature with appropriate thermodynamic and kinetic features at the typically low concentrations used. Ideally, the chemoselective reversible reaction should be biorthogonal, but the groups of Matile and Adibekian have interestingly shown that a transient cross-reaction with biomolecular constituents of the cell membrane can assist cell penetration (vide infra). ${ }^{116}$ To date, carbonyl condensation reactions, disulphide bond, boronate ester remain the most popular choice (Fig. 3).

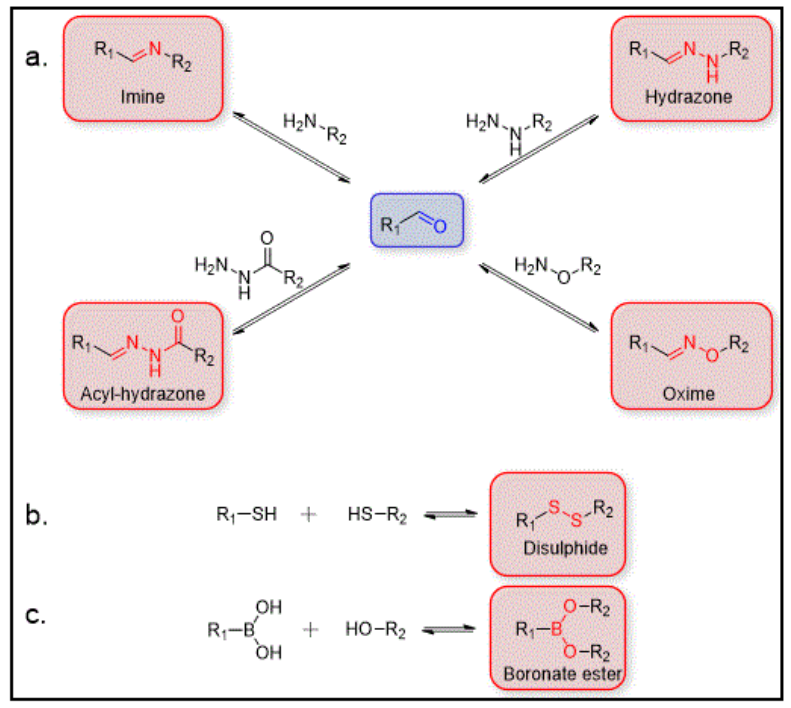

Fig. 3 Reversible covalent reactions: (a) amino/carbonyl condensation, (b) sulphide/disulphide and (c) boronate ester reactions. 
One of the most popular chemistries used for the construction of scaffolds for gene transfection is the iminetype condensation reaction between carbonyls (aldehyde or ketone) and primary amine groups. Playing with the $\alpha$-effect give access to different types of conjugates, such as imines, oxime, hydrazones and acyl-hydrazones depending on the selected nucleophile, which have different thermodynamic stabilities in aqueous media and kinetics of formation. ${ }^{117,118}$ Imines are widely used because of straightforward synthesis, but they usually revert back to carbonyl compound and primary amine too quickly in aqueous media. ${ }^{119}$ Research on their hydrolysis have shown that oxime linkages presents better performance on hydrolytic stability compared to imines. ${ }^{117,120}$ Sitting somewhere in between, acyl-hydrazones are of interest since they show sufficient stability while remaining dynamic on a reasonable time-scale (typically hours to days depending on the conditions). Placing assisting groups next to the reactive moieties has been shown to modulate the stability and kinetics of formation and exchange reactions, ${ }^{121}$ 124 allowing fine tuning those conditions by molecular engineering. For example, an ortho boronic acid substituent for aryl ketones can significantly stabilize the corresponding imines at neutral pH (Fig. 4), while its conjugation with phenylhydrazine takes place with rate constants as high as $10^{3}$ $\mathrm{M}^{-1} \mathrm{~S}^{-1}{ }^{122}$ Alternatively, nucleophilic catalysts can also be used. ${ }^{125-130}$ Importantly for nucleic acid delivery where endosome escape is a common issue that can be addressed using $\mathrm{pH}$-responsive systems, acyl-hydrazones are acidsensitive and are typically hydrolysed at acidic $\mathrm{pH}(\mathrm{pH} \approx 4-6)$. Finally, all those $\mathrm{C}=\mathrm{N}$ groups may feature double dynamic processes, configurational and constitutional dynamics, ${ }^{131,132}$ which in principle can be used to provide an handle over their biological activity. ${ }^{133}$

Disulphide bond is triggered by thiol oxidation and this redoxcontrolled reversible process plays a great role in stabilizing the 3D-folded of proteins. Disulphide exchange require thiol deprotonation and the formation of an active thiolate anion making this chemistry adaptive at basic $\mathrm{pH} .{ }^{134,135}$ Disulphidebased dynamic carriers have been exploited in the design of nucleic acid delivery carriers, ${ }^{136,137}$ where glutathionemediated biodegradation can be applied to facilitate gene

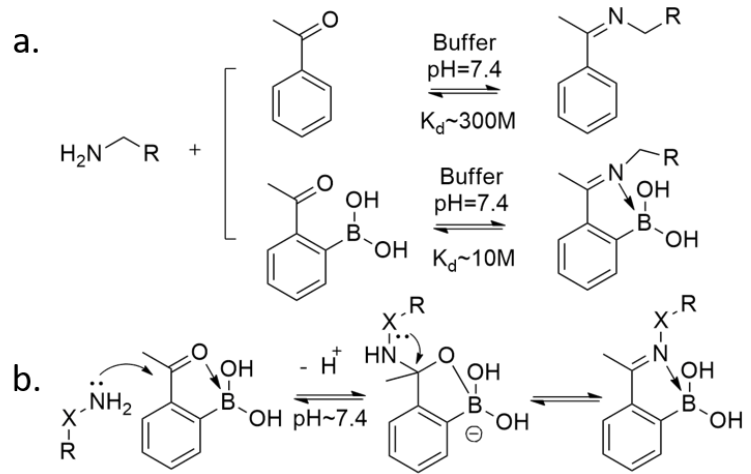

Fig. 4 (a) Effect of ortho boronic acid substituent on imine formation at neutral pH; and (b) mechanism proposed for explaining the rapid formation of iminoboronates derived from $\alpha$-nucleophiles.

release from polyplexes cargo. This method provides a safe and efficient gene delivery in the intracellular compartment where the concentration of glutathione reaches the $\mathrm{mM}$ range. ${ }^{138}$ As further discussed below, disulphide exchange reactions have also been shown to take place in situ with constituents of cell membranes.

Boronate esters can be formed though reversible condensation reactions between boronic acids (i.e. boric or phenylboronic acid) and vicinal diols, especially cis-1, 2- and 1, 3-diols. At present, and despite their popularity as reversible covalent bond, boronate esters have received little interest for making dynamic covalent polymers for gene delivery, most likely due to their limited association constants in aqueous media. Nevertheless, boronic esters can be interestingly used to break down polyplexes - though oxidization triggered by reactive oxygen species in physiological condition - and then release nucleic acid. ${ }^{139,140}$ A tailored dual-responsive gene delivery vehicle was formulated via boronic acid chemistry, displaying appreciable endosome escape and rapid gene liberation. ${ }^{140}$

\section{Architectures of cationic dynamic covalent polymers}

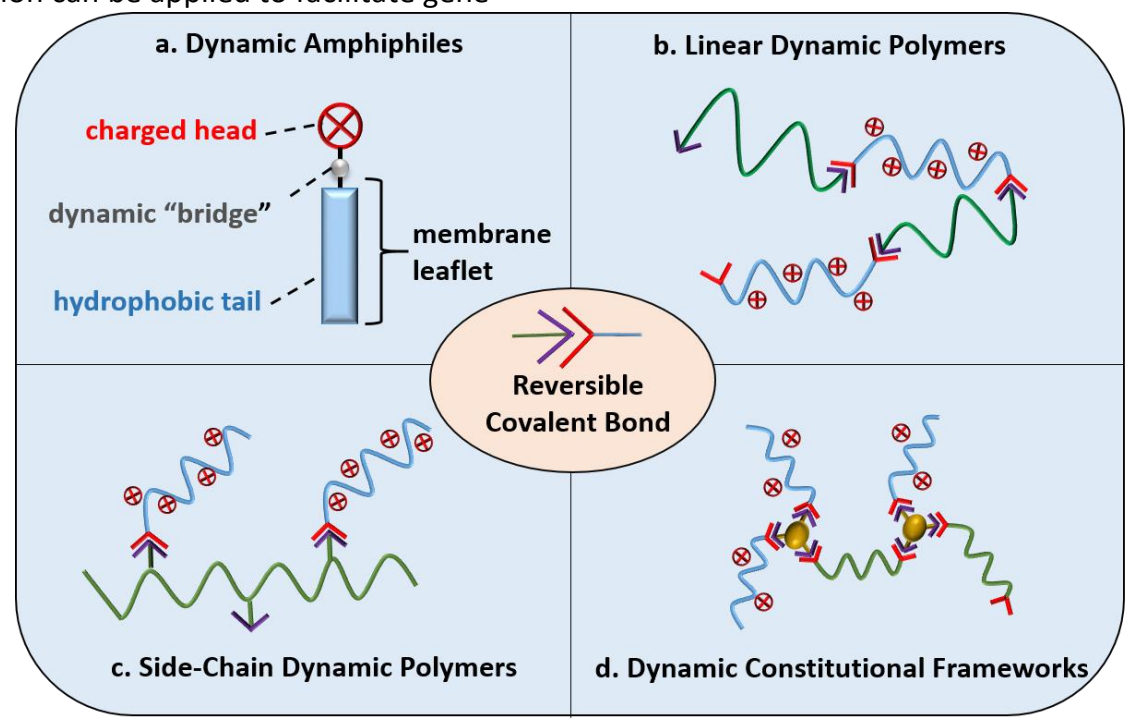

Fig. 5 Architectures cationic dynamic covalent vectors used in gene delivery: (a) dynamic amphiphiles, (b) linear dynamic polymers, (c) side-chain dynamic polymers, and (d) dynamic constitutional frameworks. 
One of the early contributions to gene delivery using dynamic covalent chemistry was the development of dynamic cationic amphiphiles (Fig. 5a) that are self-assembled by DCC through the direct in situ conjugation between cationic heads and lipophilic tails. Then, capitalizing on the multivalent binding often expressed by cationic polymers, different architectures of cationic dynamic covalent polymers - from linear to $2 \mathrm{D}$ and 3D - have been explored for gene delivery: i) linear dynamic polymers (Fig. 5b), ii) side-chain dynamic polymers (Fig. 5c), and iii) dynamic constitutional frameworks (Fig. 5d).

\subsection{Dynamic cationic amphiphiles}

Amphiphilic cations have been designed to complex anionic nucleic acids and the cellular uptake capacity of the counteranion-activated DNA have been demonstrated. ${ }^{67,83,141}$ For example, calixarene macrocycles have been used to combine multiple guanidinium cations to form counteranion activators as cation transporters. ${ }^{83}$ The conical architecture of calixarenes provided a wide space to spatially fix multiple cationic substituents around the rim of the unique macrocyclic structure. Tetra- or hexa- guanidinium cations with diverse amphiphilicity were used to complex DNA.

Beyond this, dynamic amphiphiles complexes which are constructed by combining charged heads with hydrophobic tails through reversible linkages (Fig 5a), ${ }^{75}$ are capable of mediating nucleic acids as well as of penetrating through lipid bilayer membranes, representing a privileged choice for achieving cellular uptake and gene transfection. ${ }^{96,142,143}$ Moreover, the appropriate selection of the reversible covalent reaction can impart redox or $\mathrm{pH}$ sensitivity to the amphiphilic self-assembly and, thereby, a control over the delivery of nucleic acids.

Lehn and co-workers reported early on an example of dynamic amphiphile where the cationic head and the lipophilic tail is connected through a single $\mathrm{pH}$-sensitive acyl-hydrazone bond. ${ }^{144,145}$ Matile and coworkers reported dynamic octopus amphiphiles, (Fig. 6) composed of guanidinium cation "head" and hydrophobic "tails". ${ }^{146,147}$ In these systems, tetrahydrazides as hydrophilic counterions provided fourtailed octopus amphiphiles to multivalently bind the nucleic acid. Hydrazone, oxime and disulphide linkages were used to expand their library by means of various dynamic cationic amphiphiles with double charged heads and four hydrophobic tails. $^{75}$ These multi-tails counterion transporters were synthesized for the activation of DNA and a comprehensive screening of these dynamic polyion-counterion complexes showed potential application toward sensing ${ }^{148}$ and cellular uptake. ${ }^{142,149}$

Dynamic cationic amphiphiles are attractive multicomponent delivery platforms that combine the advantages of i) cationic hydrophilic head groups for condensation of genes, ii) membrane compatibility of hydrophobic tails, and iii) reversible covalent bonds that endow responsiveness. Structure-activity relationships can be elucidated through fragments screening and in situ self-assembly of structurallydiverse components constituting the cationic amphiphiles. By means of chemoselective reversible covalent bonds that can be formed in situ, dynamic cationic amphiphiles can be constructed to quite large and complex libraries with hundreds

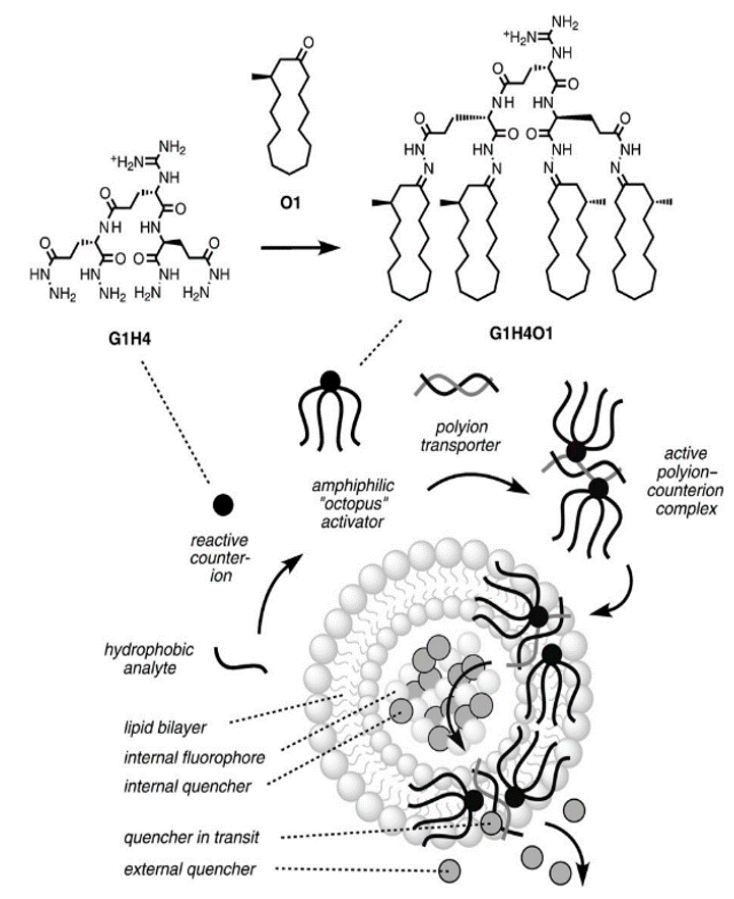

Fig. 6 Covalent self-assembly of octopus amphiphiles for polyion transport. ${ }^{147}$ Reproduced with permission from ref. 147. Copyright 2010 WILEY - VCH.

of combinations. A large library with 900 dynamic cationic amphiphiles was generated using 18 heads and 50 tails, leading to the identification of 160 candidates out of the 900 possibilities which were taken further for cellular uptake as "artificial noses" for siRNA delivery. ${ }^{150}$

These dynamic cationic amphiphiles present great abilities to complex nucleic acids and transfect them through cell membranes with high reproducibility and low toxicity. A moderate number of dynamic cationic amphiphiles were generated for rapid identification and screening, thereby this methodology based on dynamic cationic amphiphiles presents a considerable potential for gene delivery.

\subsection{Linear dynamic polymers-dynamers}

Linear dynamic polymers are formed by the reversible association of ditopic monomers, and thus contain the reversible linkage in their main chain. This feature makes them dynamic not only in terms of incorporation/decorporation of monomers but also in terms of chain extension and contraction.

The group of Seymour reported early on an elegant strategy using disulphide formation as reversible covalent reaction on cationic peptides end-terminated with cysteines at both $\mathrm{N}$ and

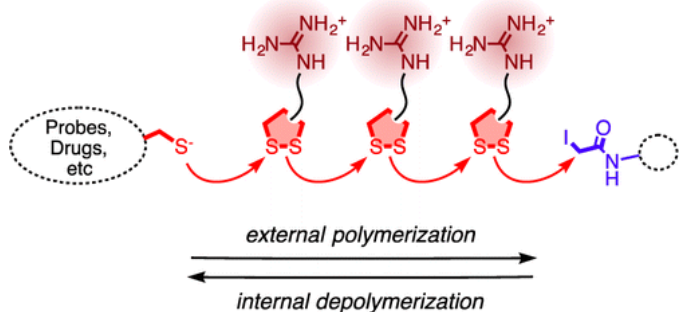

Fig. 7 Formation of cationic linear cell-penetrating poly(disulphide)s vectors by ringopening polymerization. ${ }^{151}$ Reproduced with permission from ref. 151. Copyright 2013 American Chemical Society. 

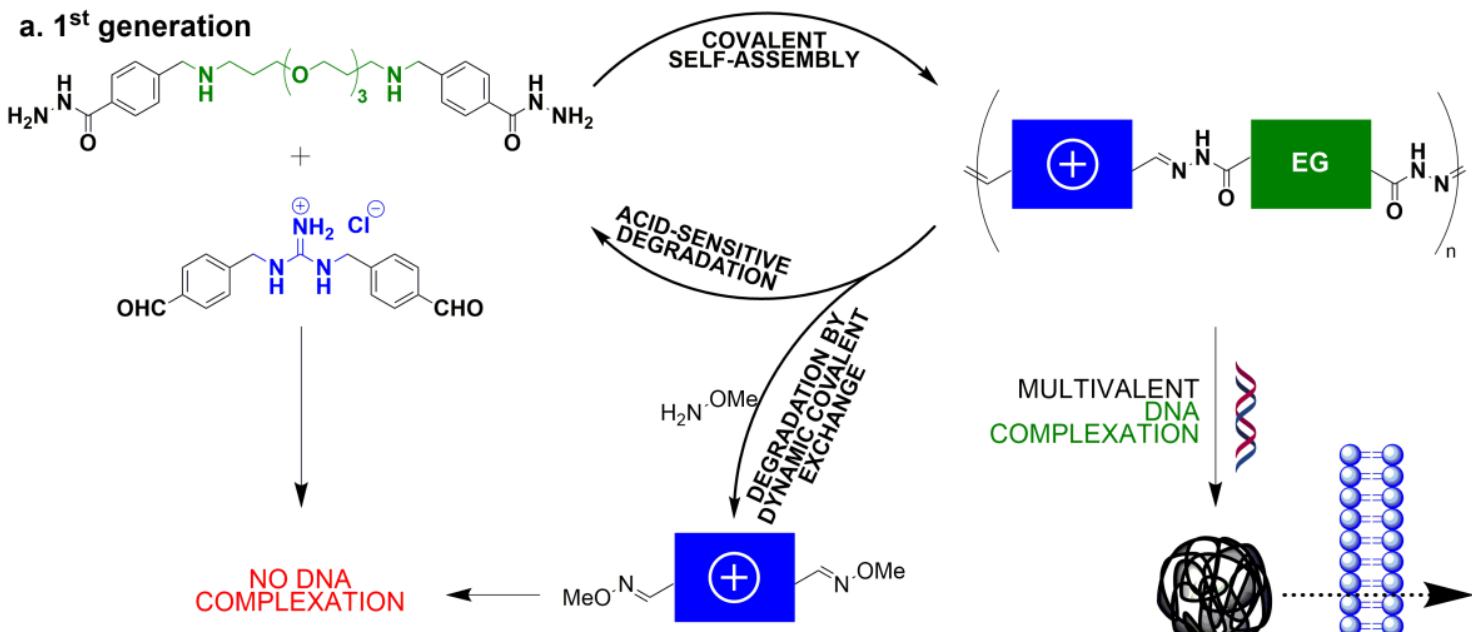

b. $2^{\text {nd }}$ generation
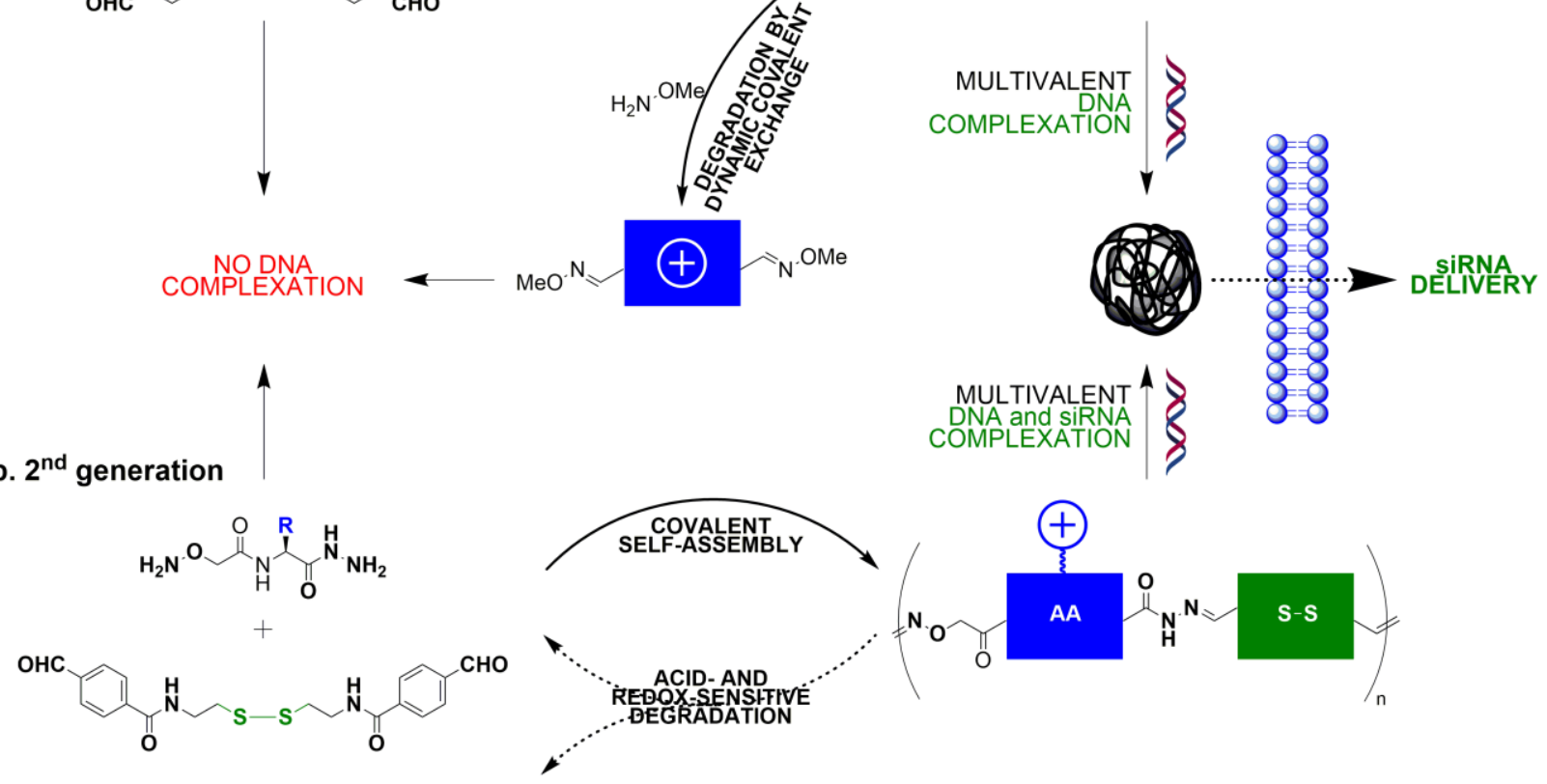

Fig. 8 Dynamic covalent assembly of linear dynamic covalent polymers for DNA complexation and siRNA delivery. ${ }^{21}$ Reproduced with permission from ref. 21 . Copyright 2019 American Chemical Society.

C termini. Oxidative polymerization lead to cationic polymers able to complex DNA and to undergo intracellular reductive depolymerization. ${ }^{152}$ The delivery and controlled release intracellularly of gene in live cells has been carried out by using cell-penetrating poly(disulphides) (CPDs), this can provide an efficient solution to minimize cytotoxicity in the field of gene transfection. ${ }^{153}$ Matile's group have exploited dynamic cationic linear CPDs synthesised through ring-opening disulphide exchange. ${ }^{154,155}$ In their design, guanidinium cations were first covalently connected to a strained disulphide, linear carriers were grown by substrates-mediated polymerization subsequently (Fig. 7). ${ }^{151}$ The implantation of disulphide ring may facilitate thiol-mediated cellular uptake and achieve controlled release of targets by reductive depolymerization. ${ }^{116,156,157}$ Indeed, those CPDs rapidly depolymerize by monomer removal through self-cyclization within minutes after intracellular reduction, and their variable length has been shown to determine their cellular localization. ${ }^{155,158}$ Glycosylation with $\alpha$-D-glucose, $\beta$-Dgalactose, D-trehalose, and triethyleneglycol has been later used to increase the solubility of classical CPDs and to achieve multifunctional cellular uptake. ${ }^{159}$ The results indeed indicate better cell uptake in the cytosol and nucleus together with a reduced cytotoxicity, the CPD bearing $\alpha$-D-glucose being the most active. Also, a role for the sugar-receptor interaction at the cell surface in the cell penetration process has been evidenced by competition experiments, cell penetration being hampered by large excess of D-glucose but not with L-glucose.

Ulrich and co-workers have synthesised linear dynamic covalent polymers though a polycondensation process exploiting acyl-hydrazone linkages (Fig. 8a). ${ }^{76}$ The first generation of these linear hybrid dynamers was designed to combine guanidinium-based or ethyleneimine cationic groups with short ethylene-glycol chains. The results show that oligomers do indeed self-assemble when the polycondensation reaction is carried out at high concentration (typically $>50$ $\mathrm{mM}$ ), and that the resulting dynamers display multivalent binding to plasmid DNA in aqueous buffer as well as in biological serum. ${ }^{160}$ Moreover, the acyl-hydrazone-based dynamers have been shown to be $\mathrm{pH}$-sensitive and to undergo degradation at $\mathrm{pH} \approx 5$ corresponding to the $\mathrm{pH}$ of late endosomes, while remaining stable over much longer period of time at physiological $\mathrm{pH}$.

The second generation of linear dynamers includes modified amino acids and involve acyl-hydrazone and oxime condensation reactions for polymer formation (Fig. 8b). ${ }^{161}$ This more versatile synthetic approach enabled testing different modified amino acids (Arg, Hys, Lys) and arginine stood out for imparting better binding to DNA. Combination of the $\mathrm{pH}$ sensitive acyl-hydrazone reversible covalent bond with the redox-sensitive disulphide bond could also be achieved for making dual-responsive dynamers. The results obtained through fluorescence displacement assays and gel electrophoresis demonstrate good complexation not only to long dsDNA but also to short siRNA. Biological experiments on live cells reported an effective transfection of siRNA - even surpassing lipofectamine - with limited cytotoxicity. 
<smiles>CC(C)(CC(C(=O)NN)C(C)(C)S)C(=O)O</smiles>

P1

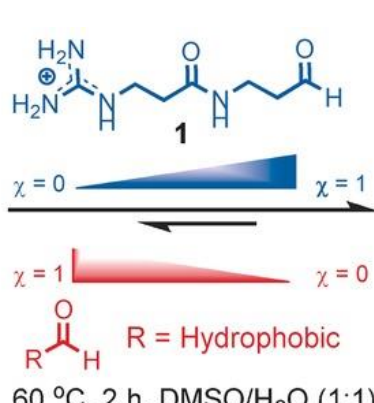

$60{ }^{\circ} \mathrm{C}, 2 \mathrm{~h}, \mathrm{DMSO} / \mathrm{H}_{2} \mathrm{O}(1: 1)$
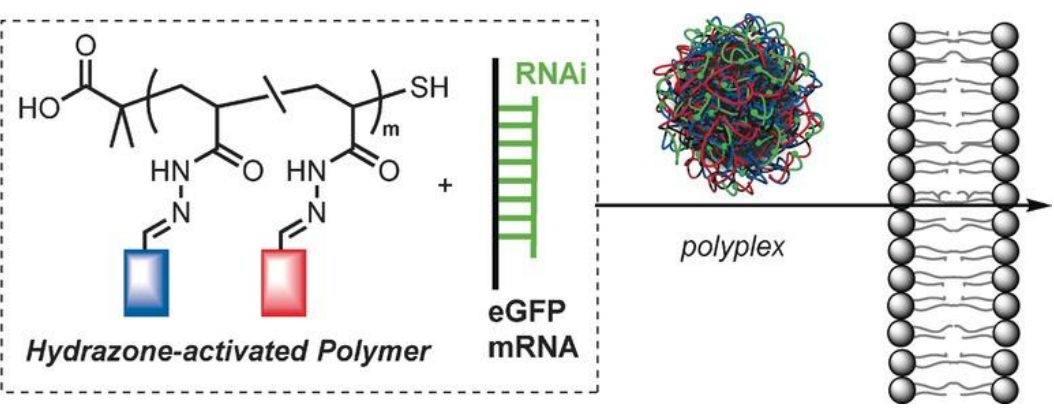

Fig. 9 Dynamic functionalization of polyhydrazide polymers by cationic and lipophilic aldehydes for identifying amphiphilic vectors of nucleic acids. ${ }^{162}$ Reproduced with permission from ref. 162. Copyright 2016 WILEY - VCH.
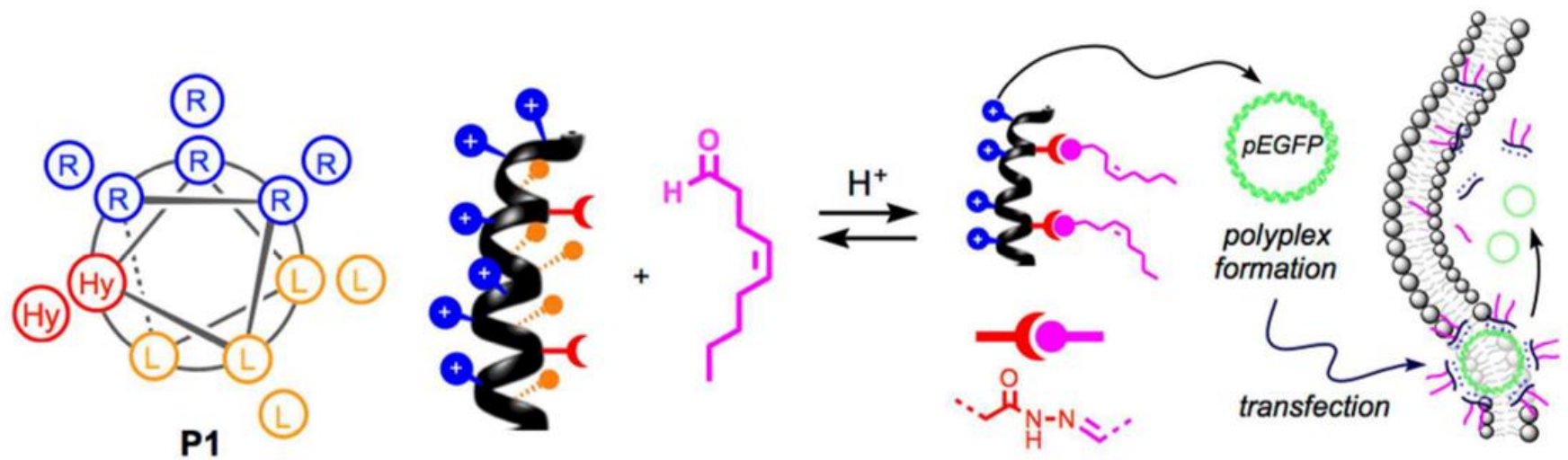

Fig. 10 Peptide-scaffolded side-chain dynamic covalent polymers for the intracellular delivery of plasmid DNA, with wheel diagram representing the helical conformation of facial amphiphilic peptide scaffold P1. ${ }^{163}$ Reproduced with permission from ref. 163. Copyright 2017 Royal Society of Chemistry.

\subsection{Side-chain dynamic polymers}

Side-chain dynamic polymers are made of non-dynamic polymers connected to multiple functional side-chains through reversible reactions such as acyl-hydrazone ${ }^{162}$ and disulphide. ${ }^{152}$ The length of side-chain dynamic polymers is therefore imposed by the structure of the polymer scaffold and it is their decoration which is susceptible to adaptation by constitutional exchange processes - the number and positions of those side-groups being imposed by the number and position of the reactional handles introduced in the polymer scaffold. ${ }^{164-166}$ Fernandez-Trillo, Montenegro and co-workers used poly-acryloyl polymer scaffolds bearing multiple hydrazide groups to prepare amphiphilic vectors through a covalent self-assembly approach (Fig. 9). ${ }^{162,163,167-169}$ Polymers of different lengths were functionalized, via acyl-hydrazone chemistry, with varying ratio of cationic and lipophilic aldehydes. Subsequently, a rapid and effective in cellulo screening enabled the identification of the best nucleic acid vectors.

Montenegro's group then exploited a helical linear peptide as pre-organized scaffold presenting lipophilic and cationic hydrophilic faces (Fig. 10).163 Two reactive hydrazide connectors were placed on this main chain and the same dynamic post-functionalization approach was implemented using a library of hydrophobic aldehydes. It was found that the lipophilic side-chain affected the secondary folding of the peptide scaffold and its overall amphiphilicity, thereby strongly affecting subsequent interactions with nucleic acids and cell membranes. In the end, the screening was successful and led to the identification of an effective vector of plasmid DNA.

More recently, the Montenegro group reported the design, synthesis, and biological evaluation of glycosylated cellpenetrating peptides based on their original design of sidechain dynamic polymers. ${ }^{170}$ Two identical glycans such as $\alpha$-Dmannose, $\quad \beta$-D-glucose, $\quad \mathrm{N}$-acetyl- $\beta$-D-glucosamine, $\quad \beta$-Dgalactose, and a branched trisaccharide of $\alpha$-D-mannose were anchored onto the peptide through oxime ligation. Excellent cell penetrating activities have been observed with improved uptake efficiency/cytotoxicity balance. Unfortunately, the screening of different glycans indicate that cell penetration is mainly imparted by the peptide and not by the glycan residue, thereby limiting for the moment the potential of this approach for achieving cell-selective delivery.

\subsection{Dynamic constitutional Frameworks - DCFs}

Examples of reversible cross-linking of cationic peptides have been reported early on using disulphide chemistry. ${ }^{171-173}$ More recently, imine-based Dynamic constitutional frameworks DCFs have been proposed by Barboiu and co-workers for adaptive gene recognition and cell-transfection. ${ }^{174,175,176}$ Poly(ethylene glycol)-bis(3-aminopropyl) terminated, spermine and Jeffamine were used as connecting building blocks and connector centres, linked together by labile, reversible 


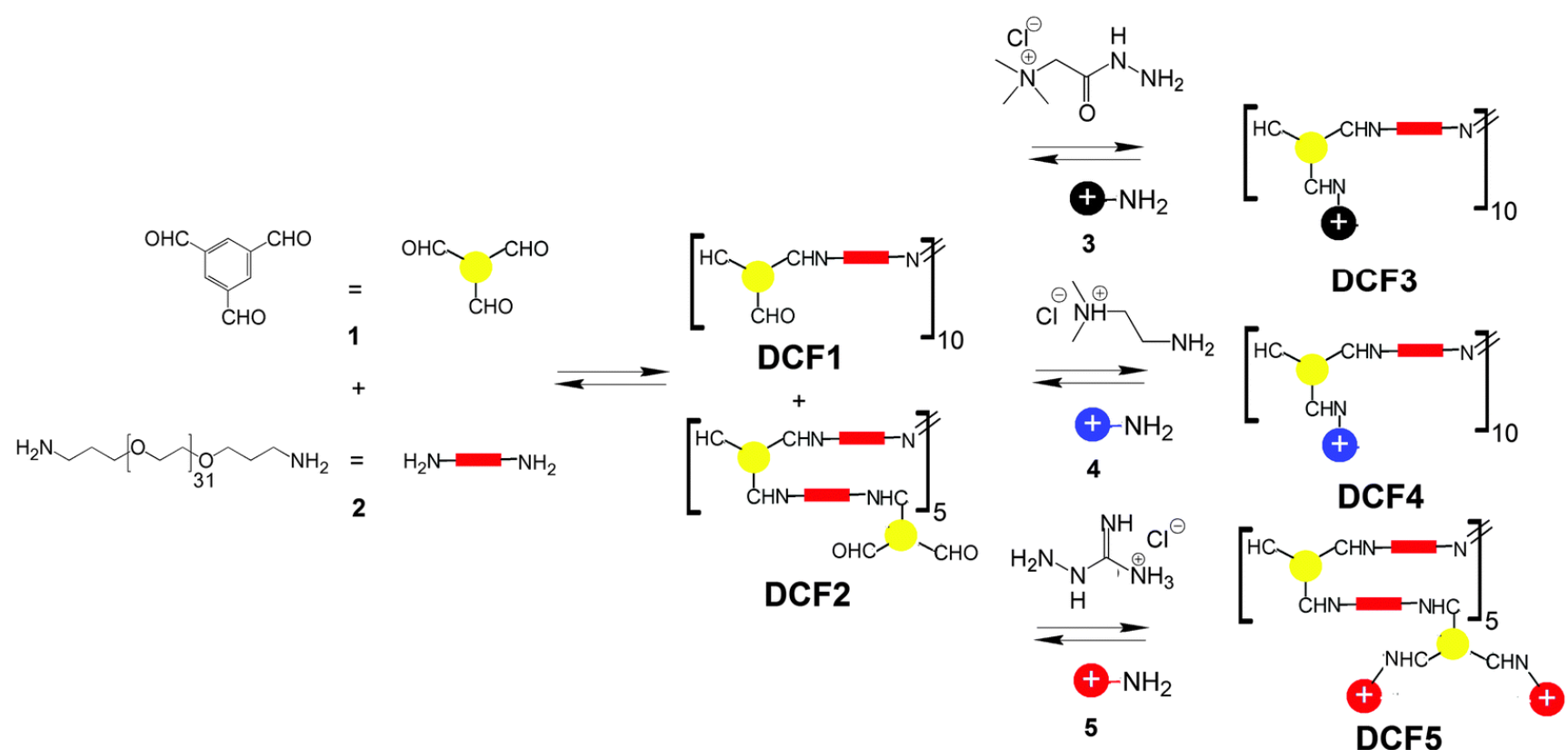

Fig. 11 Dynamic constitutional frameworks for DNA recognition; DCF synthesis combining PEG, 2 and 1,3,5 benzene-trialdehyde cores 1, resulting in the formation of neutral DCFs 1 and2, followed by treatment with positively charged heads to led to the final cationic DCFs $3-5 .{ }^{174}$ Reproduced with permission from ref. 174 . Copyright 2015 Royal Society of Chemistry.

covalent bonds to form cross-linked 3D scaffolding platforms. Cationic blocks have been attached in the head of scaffolds to form hydrophilic corona, giving them the ability to electrostatically bind nucleic acids. Importantly, they undergo exchange, incorporation/decorporation of their subunits, synergistically interacting and adapting the overall 3D nanostructure in the presence of DNA and bilayer membrane environment. The core scaffolds used for the formation of the DCF are multivalent platforms with multivalent binding affinity towards nucleic acids. This might play an important role in the ability to finely mutate and adaptively implement reversible rearrangements of the components, toward a high level of correlativity of their hypersurfaces in interaction with the DNA and the cell membrane barrier. This means that gene biotargets can self-select their optimal and functional DyNAvector from a mixture of reversible 3D DCFs. The DCF strategy showed an easy and efficient identification and rapid screening for DNA recognition and transfection. The DCFs are highly soluble in water and mainly positive charged when in physiological conditions, to increase the possible interaction with the negatively charged phosphates groups on the DNA. The incipient development of DCFs have been described by Barboiu and co-workers in 2015 showing that PEG macromonomers, trialdehyde core connectors and positively charged heads can be used to generate DCFs for DNA recognition (Fig. 11). The ability of DCF1-5 to bind negative dsDNA was evaluated using the agarose gel retardation assays and DNA-binding affinity is related to the greater capacity of the guanidinium vs. ammonium group to interact with phosphodiesters of DNA. ${ }^{13}$ The simplicity and robustness of the synthetic strategy allow rapid screening of conditions for generating systems with optimal synergistic DNA binding affinities.
The next generations of DCFs was designed in order to obtain good transfection efficiency and a low cytotoxicity. ${ }^{176,177}$ Barboiu et al. described the synthesis and characterization of a class of PEI based DCFs, co-self-assembled with PEG components and leading to adaptive spatial distributions in the presence of interacting DNA biotargets (Fig. 12). ${ }^{177} \mathrm{PEI}$ is one of the most studied synthetic cationic DNA vectors and branched PEI of high molecular weight is considered to be one of the most efficient gene carrier for plasmid DNA, oligonucleotides and small interfering RNAs (siRNA)s. The high transfection efficiency for PEI/DNA polyplexes is attributed to the unique capacity of PEI to buffer endosomes. However, the

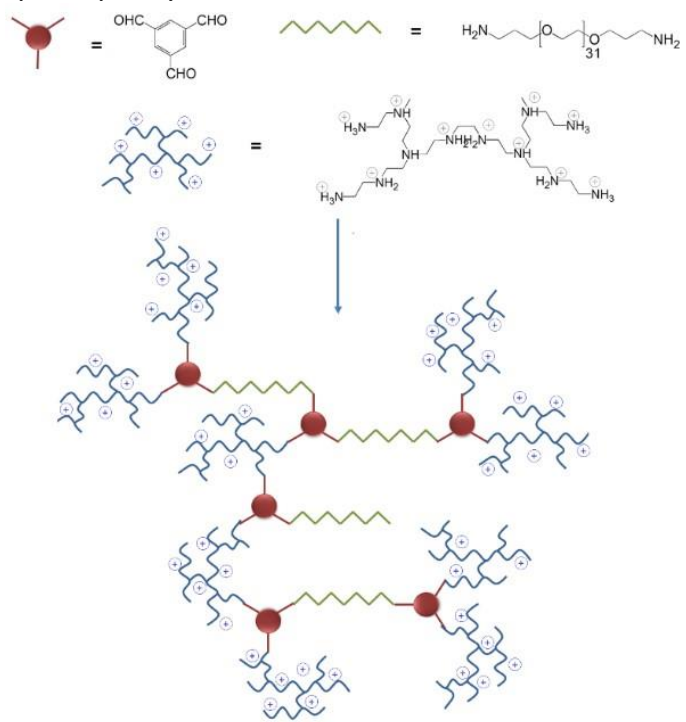

Fig. 12 Dynamic constitutional frameworks containing PEI/PEG components for DNA recognition and transfection. ${ }^{177}$ Reproduced with permission from ref. 177. Copyright 2015 Royal Society of Chemistry. 
a

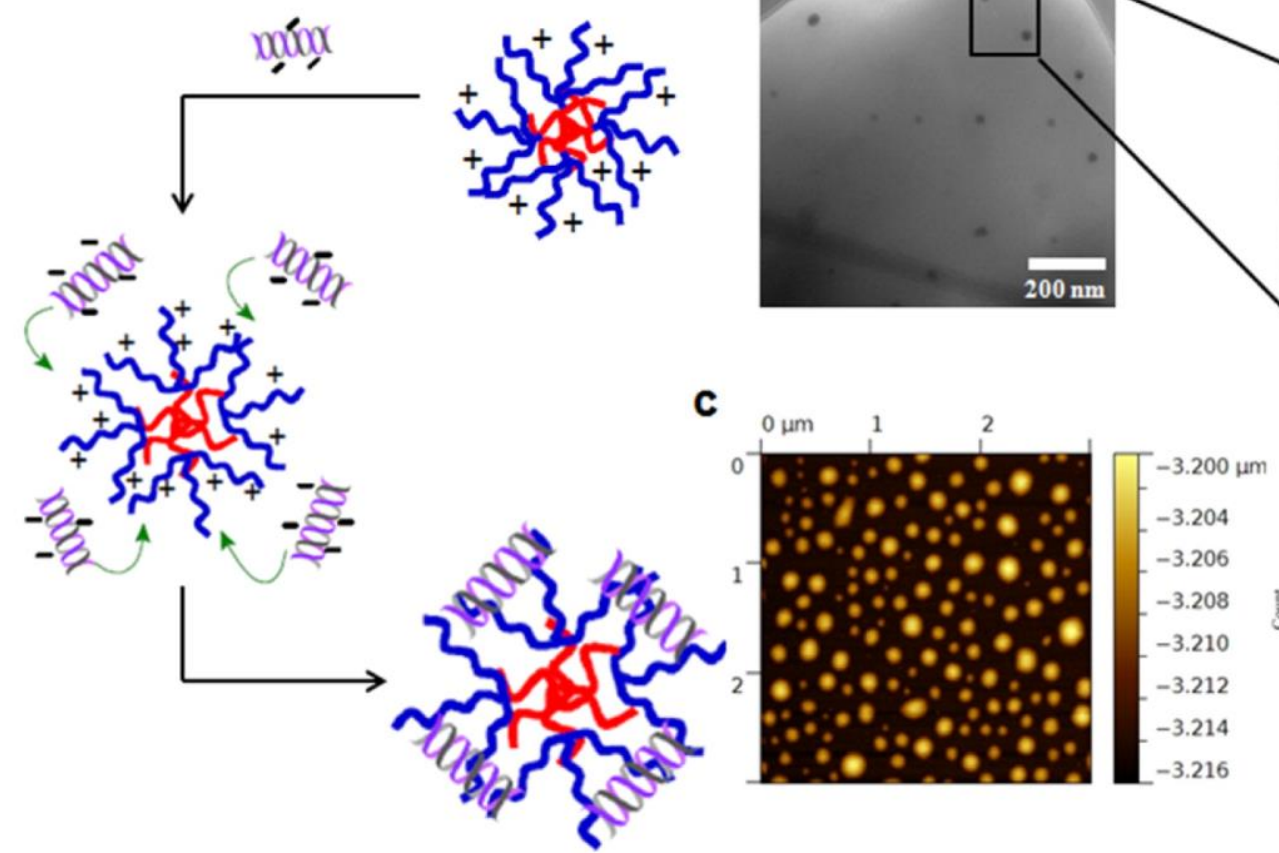

b

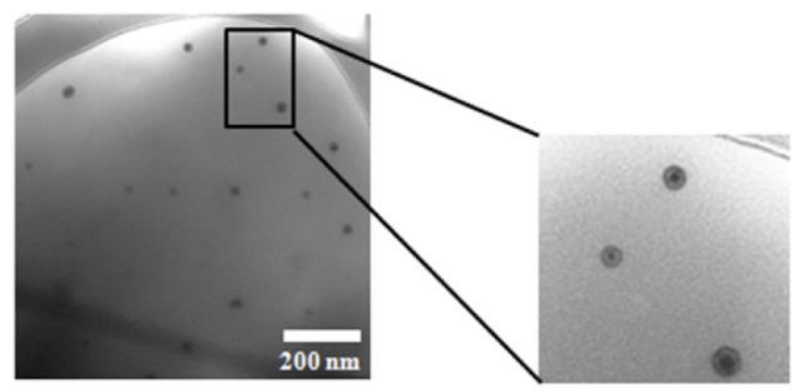

Fig. 13 Dynamic constitutional frameworks containing hydrophobic/hydrophilic components for DNA recognition and transfection: a) The proposed self-aggregation mechanism in the formation of DCF/DNA polyplexes; b) TEM image for corona DCF particles; c) AFM image and particle size distribution for DCF/plasmid pEYFP at N/P=100. ${ }^{178}$ Reproduced with permission from ref. 178. Copyright 2015 American Chemical Society.

use of PEI in vivo and in vitro gene delivery is limited because of its low colloidal stability and its considerable cytotoxicity. To enhance stability and biocompatibility of PEI polyplexes, they can be combined with PEG; however, PEGs shield the positive charges of PEI, which often has the undesired effect of decreasing transfection efficiency. The PEI-based DCFs are able to act as vectors, by forming stable polyplexes with dsDNA ranging between 40 and $125 \mathrm{~nm}$. All tested vectors were capable of transfecting DNA into HeLa cells and demonstrated low cytotoxic levels; even at an $\mathrm{N} / \mathrm{P}=\mathbf{2 0 0}$ cell viability is over $90 \%$. We can conclude that the presence of the PEG component and a moderate amount of b-PEI in DCFs are both important in the construction of highly transfecting and cytofriendly polyplexes, well tolerated by cells. ${ }^{177}$

Reversible recombination of cationic heads with hydrophilic and hydrophobic DCF-constitutive building blocks result in the formation the multivalent core-shell DCF architectures with an optimal diameter of $100 \mathrm{~nm}$ that may be adaptively generated in the presence of DNA targets (Fig. 13). ${ }^{178}$ The fittest DCFs simultaneously exhibit optimal DNA binding, superior transfection yield to standard transfection SuperFect agent and preserve high HEK $293 \mathrm{~T}$ cell viability. ${ }^{176}$ Similarly a multivalent polycationic structure with aromatic-guanidinium heads may be generated through imine bridges between 1,3,5benzenetrialdehyde and tri(2-aminoethyl)amine. This provides an alternative method to design polymeric polyplexes for gene delivery. ${ }^{77}$

Adaptive DCF vectors can be synthesized via constitutional self-assembly of PEG and squalene components with $b$ PEI cationic binding groups with the core centers around the DNA biotargets (Fig. 14). They adaptively generate micellar polyplexes with variable sizes that transfect HeLa cells and proved low cytotoxic levels. Using different molar and N/P ratios among components or in combination with DNA,

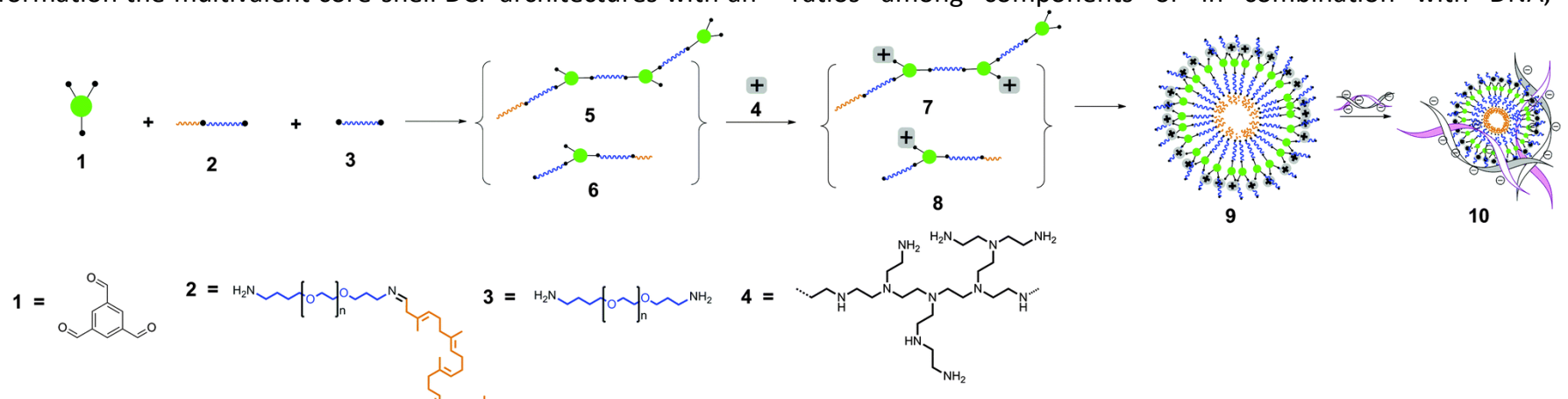

Fig. 14 Squalene-based self-assembly 9 results in the formation of DyNAvector nanoparticles binding DNA to form polyplex 10 used for gene delivery. 1,3,5-benzenetrialdehyde 1 core-connectors, Squalene-PEG 2 and PEG 3, segments and DNA binding sites bPEl 4. The intermediary units 5, $\mathbf{6}$ resulted after combination of components 1-3 have been combined with 4 to give multivalent charged unit, 7, 8. ${ }^{179}$ Reproduced with permission from ref. 179 Copyright 2015 Royal Society of Chemistry. 
spherical and tube-liked core-shell particles can be synergistically obtained as showed by transmission electron microscopy. ${ }^{179}$ The polyplexes size and polydispersity are close related to transfection efficiency of $12 \%$ at $\mathrm{N} / \mathrm{P}=50$ that can be obtained with particles < $200 \mathrm{~nm}$ diameter and a narrow polydispersity, while presenting a minimal toxicity. ${ }^{179}$

\section{Toward universal gene delivery through adaptive self-assembly}

The unique feature of dynamic covalent polymers, compared to traditional and degradable polymers, is their capacity to adapt throughout the multi-step gene delivery process.

\subsection{Adaptation to nucleic acid binding}

Adaptation of dynamic covalent polymers to nucleic acid is an interesting approach toward identifying vectors that are selffitted for one particular application (e.g. pDNA, siRNA, mRNA delivery). Interestingly this specificity does not limit the versatility of the approach since the adaptive behaviour enables in situ reconfiguration of the dynamic polymers to a different templating nucleic acid. Early examples provided proof-of-concepts for the use of dynamic combinatorial chemistry on nucleic acid targets ${ }^{180}$ but few of them addressed the application of gene delivery. In this line, we have reported constitutional adaptation of low molecular weight vectors to nucleic acids. ${ }^{84}$ Using dynamic covalent polymers, the group of Aida reported a major discovery in the field in 2015. ${ }^{181}$ They studied water-soluble telechelic dithiol monomers bearing multiple (2-4) guanidinium groups that are separated by a 7.4 $\AA$ ether spacer, fitting the regular separation of 6-7 $\AA$ between neighbouring phosphodiesters in nucleic acids (Fig. 15). Oxidative polymerization of ${ }^{\mathrm{TEG}} \mathrm{Gu}_{4}$ was carried out in the presence of siRNA using $\mathrm{Kl} / \mathrm{I}_{2}$ as oxidant, and gel electrophoresis evidence siRNA complexation at N/P $>20$ only in those oxidative conditions, while the subsequence reduction using GSH triggered siRNA release after 1 min incubation. ${ }^{T E G} \mathrm{Gu}_{3}$ showed a similar behaviour, whereas the others led to the formation of a precipitate when mixed with siRNA. Physico-chemical studies (TEM, DLS) reveal the formation of "nanocaplets" with diameters of $<10 \mathrm{~nm}$. Dialysis was used to remove the excess of unbound cationic monomers/polymers, and the numbers of bound ${ }^{{ }^{T E G} \mathrm{Gu}_{4}}$ was determined by an Ellman's assay, which confirmed a 1:1 guanidinium:phosphodiester binding stoichiometry, thereby supporting the model of a siRNA-templated polymerization (Fig. 16). Alternatively, the polyplex was incubated with $\mathrm{ZnCl}_{2}$ for selective hydrolysis of siRNA and the unbound polymers were subsequently analysed by LC-MS and revealed the formation of the hexamer of ${ }^{T E G} \mathrm{Gu}_{4}$, understandable in terms of charge compensation ( 24 positive charges in the hexamer vs. 21 negative charges per siRNA strand). All those results firmly demonstrate that oxidative polymerization takes place, and that siRNA templates the formation of the resulting polymers. Satisfyingly, this approach was successfully implemented for gene silencing using a luciferase assay on human hepatocellular carcinoma Hep3B cells. While the results reported are very encouraging, rivalling the activity of the commercial transfection reagent DharmaFECT although the amount of uptaken siRNA was five-fold smaller, the authors noted that the "rather poor cellular uptake activity can be improved when the nanocaplet is connected to arginine
peptide-Arg6", which could pinpoint to a limitation of such electrostatically-driven siRNA-templated approach leading by charge compensation to rather neutral polyplexes whereas a net positive charge is often desired for promoting cell penetration. A solution to this issue may to be insert ligands that promote cell uptake and this has recently been realized by the same group using transferrin which was non-covalently attached to the surface of the nanocaplet. ${ }^{182}$ Finally, while nucleic-acid templated polymerization can also be applied to classical non-dynamic polymers, ${ }^{183}$ it is precisely the reversible character of DCPs that will subsequently enable them to adapt their constitution throughout the delivery process as further discussed hereafter.

\subsection{Adaptation to membrane binding}

The cell membrane represents a physical barrier, made of chemical constituents that dynamically rearrange depending on the conditions, ${ }^{184}$ that polyplexes have to cross in order to reach the cytosol. The so-called "tryptophan power", 185 which was found when Trp amino acids are inserted within cellpenetrating peptides, illustrates a simple way, among other lipid-based delivery approaches, ${ }^{37}$ to improve the interaction with cell membranes in order to favour translocation. A key point in designing amphiphilic systems is the hydrophobic/hydrophilic balance and their three-dimensional presentation. Dynamic combinatorial chemistry has already been implemented on simple models to identify supramolecular transporters of ions, ${ }^{186,187}$ amino acids, ${ }^{188}$ toward adaptive separation membranes. ${ }^{20,35,189,190}$ Apart from the latter examples, works studying dynamic covalent polymers at membrane interface remain rare. Here the situation is much more complex to investigate due to multiple dynamics possibly taking place. Indeed, in addition to the constitutional dynamics described above that operate through incorporation/decorporation of monomers, dynamic covalent polymers are also involved in ring-chain equilibria. All these factors may strongly affect the translocation efficacy since, for instance, it is now well established that cyclic TAT cell penetrating peptides and cyclic PEI enter cells more effectively than their linear counterparts. ${ }^{191,192}$

Interestingly, the group of Sagan demonstrated that thioldisulphide dynamic covalent exchange reactions with cellsurface thiols can take place at the cell membrane, which was considered as a new route toward cell entry by cellpenetrating peptides exploiting a transient covalent bond. ${ }^{193}$ Using peptides appended with a single asparagusic acid residue, the groups of Matile and Adibekian have interestingly shown that such a transient cross-reaction with biomolecular constituents of the cell membrane can indeed assist cell penetration (Fig.16). ${ }^{116}$ Proteomics experiments revealed that the transferrin receptor is the biomolecular target onto which disulphide bonds establish with two cysteines following an exchange reaction. Cellular uptake was later found to be even more active with 1,2-diselenolanes compared to 1,2dithiolanes, ${ }^{194}$ with recent improvements using benzopolysulfane networks. ${ }^{195}$ These approaches have been successfully applied to the delivery of a large number of substrates (probes, peptides, proteins, artificial metalloenzyme, protein-coated quantum dots, liposomes and 


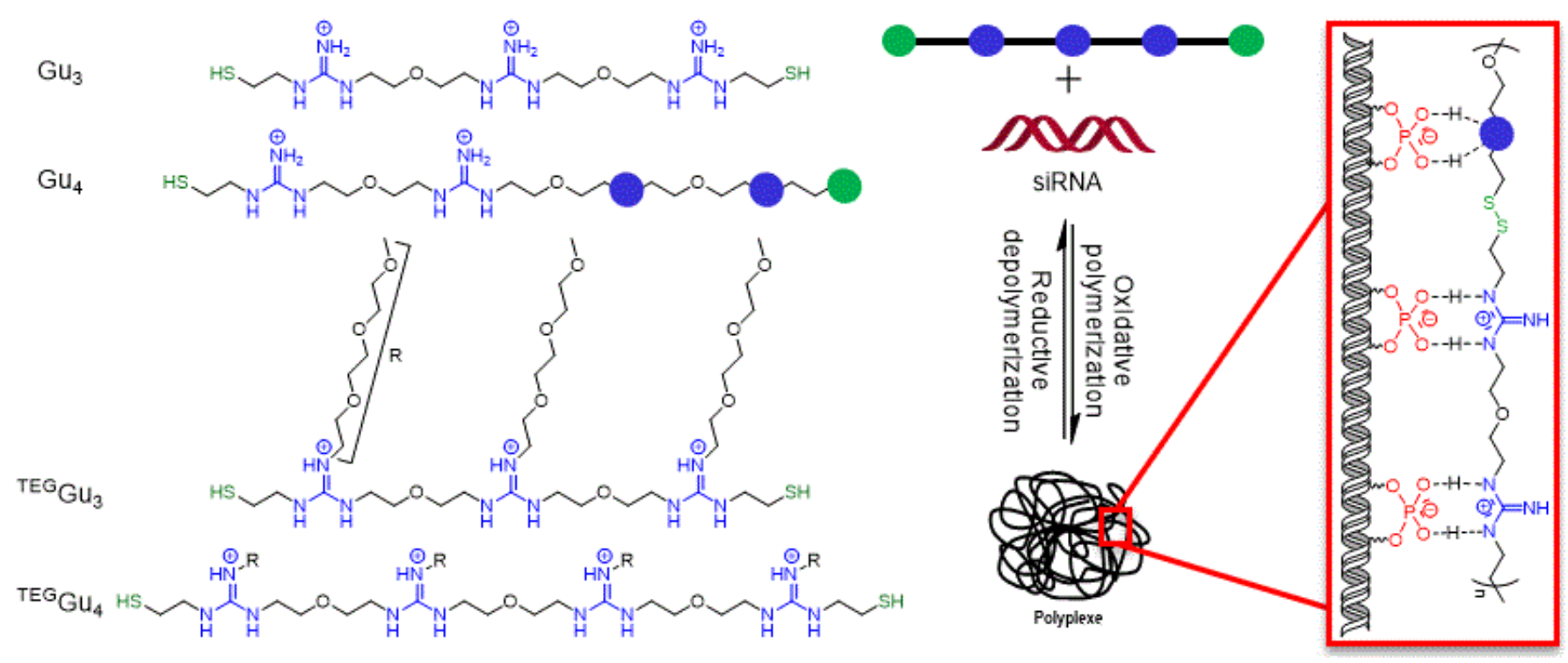

Fig. 15 Chemical structures of dithiol monomers bearing multiple guanidinium groups (left), and principle of siRNA-templated polymerization.

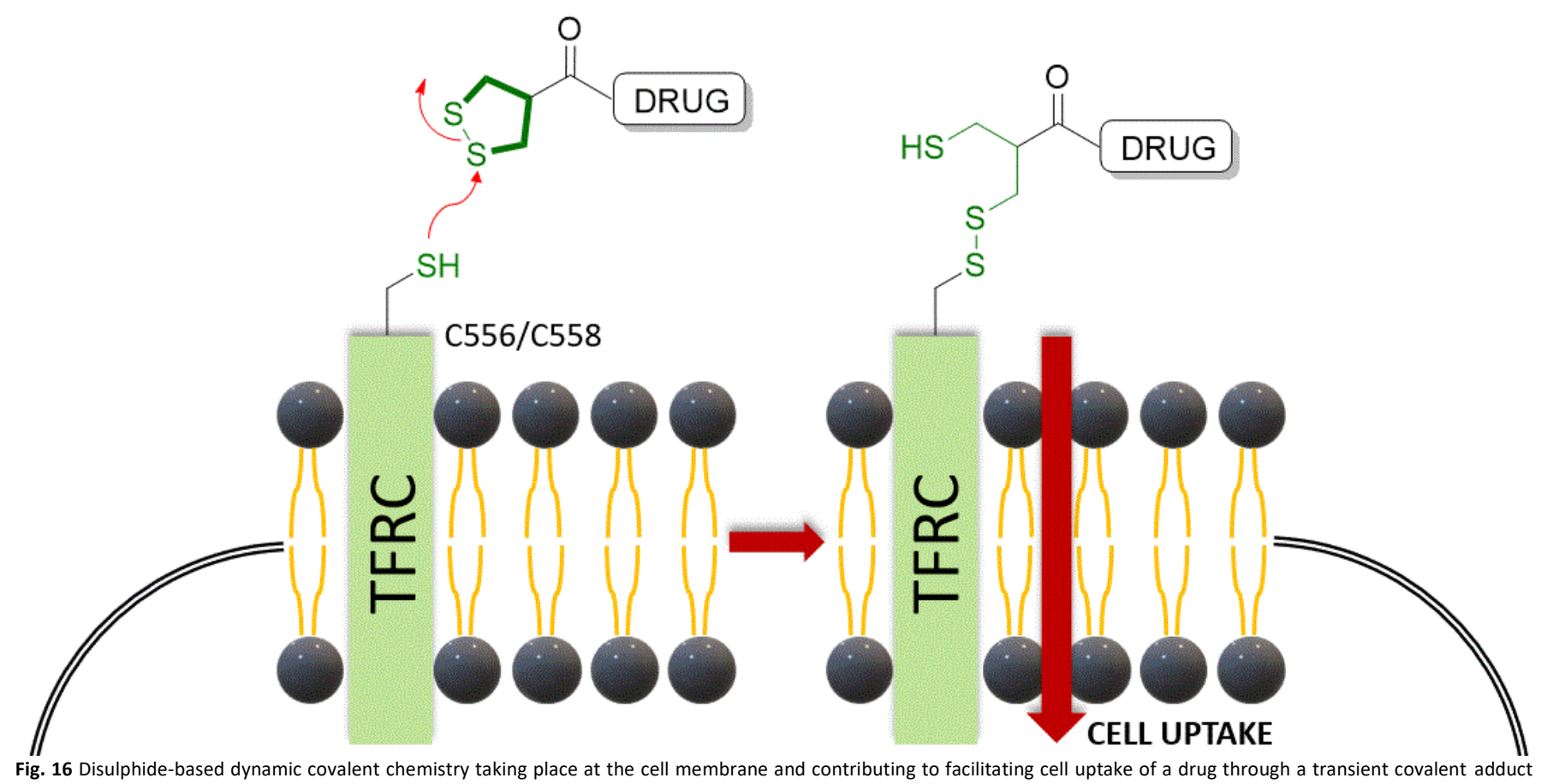

with the transferrin receptor protein 1 TFRC.

polymersomes). ${ }^{196,197}$ More recently, the Matile group disclosed the improved cell-penetrating capacities of benzopolysulfanes which form a complex dynamic-covalent network of extreme sulfur species, including cyclic oligomers, from dimers to heptamers. ${ }^{198}$ Biscysteine-bearing peptides were also found to be excellent at cell penetration, rivalling with the "Arginine Magic", thanks to their ability to establish multiple disulphide bonds with the constituents of the cell membrane. ${ }^{199,200}$

Overall, the results underscore the importance of studying dynamic covalent chemistries at the cell membrane interface in order to provide new ways to effectively enter cells. ${ }^{39}$ Undoubtedly, such new knowledge will strongly benefit the development of dynamic covalent polymers for gene delivery.

\section{Summary and outlook}

The search for synthetic polymer gene delivery vectors has been underway for a couple of decades now. The variability of nucleic acids of pharmaceutical interest has grown, along with the large number of cells to be transfected, which reinforce the interest in versatile, rapid and cheap discovery methodologies. While the rational design approach has been instrumental it does not fulfil those criteria and combinatorial screening represents a useful tool to streamline this process. Going one step further, constitutional dynamic approaches enable adaptive self-assembly to take place, leading potentially to the self-selection of the best fitted vector. Dynamic combinatorial screening is thus a simplified method 
to generate the most effective vector from complex dynamic libraries of interconverting species such as dynamic covalent polymers. Herein, we reviewed the progresses made in that direction and highlighted recent results obtained using dynamic covalent polymers for gene delivery. We summarized the current challenges that have to be addressed in gene delivery, described the structural and functional features that should be considered when designing dynamic covalent polymers, presented the reversible covalent reactions suitable for this application, and discussed in details the recent results that have been achieved using different architectures of dynamic covalent polymers: i) dynamic amphiphiles, ii) linear dynamic covalent polymers, iii) side-chain dynamic polymers, and iv) dynamic constitutional frameworks. Dynamic amphiphiles complexes are composed of charged hydrophilic heads and hydrophobic tails through reversible linkages. Linear dynamic polymers show multivalent nucleic acids complexation correlated to the dynamic self-assembly of their main-chain backbone. Side-chain dynamic polymers can hook functional molecules and achieve responsive release and endosomal escape in live cells. Dynamic constitutional frameworks DCFs allow to self-adapt and self-generate the optimal 3D architectures for gene therapy. This dynamic covalent chemistry-based strategy avoids tedious multi-step synthesis of complex compounds, instead it exploits a covalent self-assembly process to easily generate numerous constituents that can be screened and lead to the identification of effective nucleic acid vectors having high complexation ability, good transfection efficiency, and limited toxicity.

Finally, we underscored the unique feature of such a dynamic constitutional that offer great perspectives toward universal gene delivery through adaptive self-assembly using selected examples that demonstrate in situ dynamic covalent polymer formation templated by nucleic acids and their dynamic reorganization when interacting with cell membranes. The examples presented here forming the basis of this area arise mainly from parallel exploratory works studying different type of systems (different architectures, different types of positive head groups and reversible covalent linkages) and it will be important in the future to establish structure-reversibilityactivity relationships for gaining a better understanding that will help shape the future of the field. This is just the beginning of the story and much remains to be investigated to turn it into successful applications. For instance, in situ self-assembly and adaptation has been characterized in just a few systems to date, and constitutional adaptation to different types of nucleic acids and cells has to be demonstrated to validate the versatility of this approach. There, constitutional adaptation through, for instance, clustering can also be harnessed for an adaptive multivalent binding $48,201-203$ to cell membrane receptors that, in turn, should promote (selective) cell uptake. A greater control and/or fine tune of the dynamic response should also be sought.

Translating those interesting proof-of-concepts into real therapeutic applications will also require testing in vivo (e.g. zebrafish model, or mice) gene delivery using dynamic covalent polymers. Last but not least, while dynamic and degradable systems are theoretically attracting and potentially less toxic, managing the safety aspect of such dynamic systems, where interconversion between multiple species is possible, will be tricky part. But the perspectives of finding finally universal yet self-fitted synthetic gene delivery vectors through such cheap and versatile process are worthwhile the effort.

\section{Conflicts of interest}

"There are no conflicts to declare".

\section{Acknowledgements}

DS appreciates receiving a scholarship from China Scholarship Council as support at University of Montpellier, France. SU thanks the ANR (ANR-17-CE07-0042-01) for funding.

References

1 S. L. Ginn, A. K. Amaya, I. E. Alexander, M. Edelstein and M. R. Abedi, J. Gene Med., 2018, 20, e3015.

2 J. W. Gaynor, B. J. Campbell and R. Cosstick, Chem. Soc. Rev., 2010, 39, 4169-4184.

3 C. E. Dunbar, K. A. High, J. K. Joung, D. B. Kohn, K. Ozawa and M. Sadelain, Science, 2018, 359, eaan4672.

4 P. L. Felgner, T. R. Gadek, M. Holm, R. Roman, H. W. Chan, M. Wenz, J. P. Northrop, G. M. Ringold, M. Danielsen, Proc. Natl. Acad. Sci., 1987, 84, 7413-7417.

5 D. W. Pack, A. S. Hoffman, S. Pun and P. S. Stayton, Nat. Rev. Drug Discov., 2005, 4, 581-593.

6 H. Yin, R. L. Kanasty, A. A. Eltoukhy, A. J. Vegas, J. R. Dorkin and D. G. Anderson, Nat. Rev. Genet., 2014, 15, 541-555.

7 L. Peng and E. Wagner, Biomacromolecules, 2019, 20, 3613-3626.

8 R. Bholakant, H. Qian, J. Zhang, X. Huang, D. Huang, J. Feijen, Y. Zhong and W. Chen, Biomacromolecules, 2020.

9 M. A. Mintzer and E. E. Simanek, Chem. Rev., 2009, 109, 259-302.

10 P. Zhang and E. Wagner, Top. Curr. Chem. (Z), 2017, 375, pp1-39.

11 B. Dalby, S. Cates, A. Harris, E. C. Ohki, M. L. Tilkins, P. J. Price and V. C. Ciccarone, Methods, 2004, 33, 95-103.

12 U. K. Laemmli, Proc. Natl. Acad. Sci., 1975, 72, 4288-4292.

13 P. T. Corbett, J. Leclaire, L. Vial, K. R. West, J.-L. Wietor, J. K. M. Sanders and S. Otto, Chem. Rev., 2006, 106, 36523711.

14 J. N. H. Reek and S. Otto, Dynamic Combinatorial Chemistry, Wiley-VCH, Weinheim, 2010.

15 B. L. Miller, ed., Dynamic Combinatorial Chemistry In Drug Discovery, Bioorganic Chemistry, and Materials Science, John Wiley \& Sons, Inc., 2010.

16 F. B. L. Cougnon and J. K. M. Sanders, Acc. Chem. Res., 2012, 45, 2211-2221.

17 S. Ladame, Org. Biomol. Chem., 2008, 6, 219-226.

18 S. Ulrich and P. Dumy, Chem. Commun., 2014, 50, 58105825.

19 J. M. Lehn and A. V. Eliseev, Science, 2001, 291, 23312332. 
20 Y. Zhang and M. Barboiu, Chem. Rev., 2016, 116, 809-834.

21 S. Ulrich, Acc. Chem. Res., 2019, 52, 510-519.

22 J.-M. Lehn, Proc. Natl. Acad. Sci., 2002, 99, 4763-4768.

23 J.-M. Lehn, Chem. - Eur. J., 1999, 5, 2455-2463.

24 M. Barboiu, Chem. Commun., 2010, 46, 7466-7476.

25 J.-M. Lehn, Chem. Soc. Rev., 2007, 36, 151-160.

26 O. Ramström and J.-M. Lehn, Nat. Rev. Drug Discov., 2002, 1, 26-36.

27 H. Sun, C. P. Kabb, M. B. Sims and B. S. Sumerlin, Prog. Polym. Sci., 2019, 89, 61-75.

28 S. Mukherjee, J. J. Cash and B. S. Sumerlin, in Dynamic Covalent Chemistry: Principles, Reactions, and Applications, ed. W. Zhang and Y. Jin, Wiley- $\mathrm{VCH}$, Weinheim, 2017, pp. 321-358.

29 K. Imato and H. Otsuka, in Dynamic Covalent Chemistry: Principles, Reactions, and Applications, ed. W. Zhang and Y. Jin, Wiley-VCH, Weinheim, 2017, pp. 359-388.

30 F. Garcia and M. M. J. Smulders, J. Polym. Sci. Pol. Chem., 2016, 54, 3551-3577.

31 N. Roy, B. Bruchmann and J. M. Lehn, Chem. Soc. Rev., 2015, 44, 3786-3807.

32 J. M. Lehn, Aust. J. Chem., 2010, 63, 611-623.

33 T. Maeda, H. Otsuka and A. Takahara, Prog. Polym. Sci., 2009, 34, 581-604.

34 J.-M. Lehn, Prog. Polym. Sci., 2005, 30, 814-831.

35 G. Nasr, M. Barboiu, T. Ono, S. Fujii and J. M. Lehn, J. Memb. Sci., 2008, 321, 8-14.

36 U. Lächelt and E. Wagner, Chem. Rev., 2015, 115, 1104311078.

37 I. Lostalé-Seijo and J. Montenegro, Nat. Rev. Chem., 2018, 2, 258-277.

38 B. Y. Shi, M. Zheng, W. Tao, R. Chung, D. Y. Jin, D. Ghaffari and O. C. Farokhzad, Biomacromolecules, 2017, 18, 22312246.

39 J. Zhou, Z. Shao, J. Liu, Q. Duan, X. Wang, J. Li and H. Yang, ACS Appl. Bio Mater., 2020, 5, 2686-2701.

40 D. Zhou, M. Zeng, Y. Gao, A. Sigen, J. Lyu and W. Wang, in Nucleic Acid Nanotheranostics, Elsevier, 2019, pp. 311364.

41 Y. L. Cheng, D. L. Sellers, J.-K. Y. Tan, D. J. Peeler, P. J. Horner and S. H. Pun, Biomaterials, 2017, 127, 89-96.

42 D. J. Peeler, D. L. Sellers and S. H. Pun, Bioconj. Chem., 2019, 30, 350-365.

43 N. L. Benner, R. L. McClellan, C. R. Turlington, O. A. W. Haabeth, R. M. Waymouth and P. A. Wender, J. Am. Chem. Soc., 2019, 141, 8416-8421.

44 T. R. Blake, W. C. Ho, C. R. Turlington, X. Y. Zang, M. A. Huttner, P. A. Wender and R. M. Waymouth, Chem. Sci., 2020, 11, 2951-2966.

45 E. I. Geihe, C. B. Cooley, J. R. Simon, M. K. Kiesewetter, J. A. Edward, R. P. Hickerson, R. L. Kaspar, J. L. Hedrick, R. M. Waymouth and P. A. Wender, Proc. Natl. Acad. Sci., 2012, 109, 13171-13176.

46 D. J. Welsh, S. P. Jones and D. K. Smith, Angew. Chem., Int. Ed., 2009, 121, 4107-4111.

47 X. X. Liu, J. H. Zhou, T. Z. Yu, C. Chen, Q. Cheng, K. Sengupta, Y. Y. Huang, H. T. Li, C. Liu, Y. Wang, P. Posocco,
M. H. Wang, Q. Cui, S. Giorgio, M. Fermeglia, F. Q. Qu, S. Pricl, Y. H. Shi, Z. C. Liang, P. Rocchi, J. J. Rossi and L. Peng, Angew. Chem., Int. Ed., 2014, 53, 11822-11827.

48 A. Barnard and D. K. Smith, Angew. Chem., Int. Ed., 2012, 51, 6572-6581.

49 A. Barnard, P. Posocco, S. Pricl, M. Calderon, R. Haag, M. E. Hwang, V. W. T. Shum, D. W. Pack and D. K. Smith, J. Am. Chem. Soc., 2011, 133, 20288-20300.

50 P. Posocco, S. Pricl, S. Jones, A. Barnard and D. K. Smith, Chem. Sci., 2010, 1, 393-404.

51 A. Barnard, P. Posocco, M. Fermeglia, A. Tschiche, M. Calderon, S. Pricl and D. K. Smith, Org. Biomol. Chem., 2014, 12, 446-455.

52 D. J. Welsh, S. P. Jones and D. K. Smith, Angew. Chem., Int. Ed., 2009, 48, 4047-4051.

53 G. M. Pavan, A. Danani, S. Pricl and D. K. Smith, J. Am. Chem. Soc., 2009, 131, 9686-9694.

54 M. A. Kostiainen, D. K. Smith and O. Ikkala, Angew. Chem., Int. Ed., 2007, 46, 7600-7604.

55 M. A. Kostiainen, J. G. Hardy and D. K. Smith, Angew. Chem., Int. Ed., 2005, 44, 2556-2559.

56 C. Liu, X. X. Liu, P. Rocchi, F. Q. Qu, J. L. Iovanna and L. Peng, Bioconj. Chem., 2014, 25, 521-532.

57 X. X. Liu, P. Rocchi and L. Peng, New J. Chem., 2012, 36, 256-263.

58 J. H. Zhou, J. Y. Wu, N. Hafdi, J. P. Behr, P. Erbacher and L. Peng, Chem. Commun., 2006, 2362-2364.

59 O. Rolland, C. O. Turrin, A. M. Caminade and J. P. Majoral, New J. Chem., 2009, 33, 1809-1824.

60 A.-M. Caminade and J.-P. Majoral, New J. Chem., 2013, 37, 3358.

61 Y. Zhang, Y. C. Qi, S. Ulrich, M. Barboiu and O. Ramström, Mater. Chem. Front., 2020, 4, 489-506.

62 S. K. Samal, M. Dash, S. van Vlierberghe, D. L. Kaplan, E. Chiellini, C. van Blitterswijk, L. Moroni and P. Dubruel, Chem. Soc. Rev., 2012, 41, 7147-7194.

63 Z. Tan, Y. Jiang, W. Zhang, L. Karls, T. P. Lodge and T. M. Reineke, J. Am. Chem. Soc., 2019, 141, 15804-15817.

64 A. C. Rinkenauer, S. Schubert, A. Traeger and U. S. Schubert, J. Mater. Chem. B, 2015, 3, 7477-7493.

65 F. Richter, L. Martin, K. Leer, E. Moek, F. Hausig, J. C. Brendel and A. Traeger, J. Mater. Chem. B, 2020, 8, 50265041.

66 D. Sigwalt, M. Holler, J. lehl, J.-F. Nierengarten, M. Nothisen, E. Morin and J.-S. Remy, Chem. Commun., 2011, 47, 4640-4642.

67 V. Bagnacani, V. Franceschi, M. Bassi, M. Lomazzi, G. Donofrio, F. Sansone, A. Casnati and R. Ungaro, Nat. Commun., 2013, 4, 1721.

68 D. Putnam, C. A. Gentry, D. W. Pack and R. Lange, Proc. Natl. Acad. Sci., 2001, 98, 1200-1205.

69 A. C. Rinkenauer, A. Vollrath, A. Schallon, L. Tauhardt, K. Kempe, S. Schubert, D. Fischer and U. S. Schubert, ACS Comb. Sci., 2013, 15, 475-482.

70 M. R. Molla and P. A. Levkin, Adv. Mater., 2016, 28, 11591175. 
71 M. Mondal and A. K. H. Hirsch, Chem. Soc. Rev., 2015, 44, 2455-2488.

72 D. Carbajo, Y. Perez, J. Bujons and I. Alfonso, Angew. Chem., Int. Ed., 2020, 132, 1-6.

73 J. T. Goodwin and D. G. Lynn, J. Am. Chem. Soc., 1992, 114, 9197-9198.

74 B. Klekota, M. H. Hammond and B. L. Miller, Tetrahedron Lett., 1997, 38, 8639-8642.

75 J. Montenegro, E.-K. Bang, N. Sakai and S. Matile, Chem. Eur. J., 2012, 18, 10436-10443.

76 C. Bouillon, D. Paolantoni, J. C. Rote, B. Y, L. W. Peterson and P. Dumy and S. Ulrich, Chem. - Eur. J., 2014, 20, 14705-14714.

77 Y. Zhang, E. Petit and M. Barboiu, Chempluschem., 2018, 83, 354-360.

78 A. Estévez-Torres and D. Baigl, Soft Matter, 2011, 7, 67466756.

79 A. Venault, Y.-C. Huang, J. W. Lo, C.-J. Chou, A. Chinnathambi, A. Higuchi, W.-S. Chen, W.-Y. Chen and Y. Chang, J. Mater. Chem. B, 2017, 5, 4732-4744.

80 Y.-J. Shih, A. Venault, L. L. Tayo, S.-H. Chen, A. Higuchi, A. Deratani, A. Chinnathambi, S. A. Alharbi, D. Quemener and Y. Chang, Langmuir, 2017, 33, 1914-1926.

81 Z. H. Chen, Z. Y. Lv, Y. F. Sun, Z. G. Chi and G. Y. Qing, J. Mater. Chem. B, 2020, 8, 2951-2973.

82 L. Clima, E. L. Ursu, C. Cojocaru, A. Rotaru, M. Barboiu and M. Pinteala, Org. Biomol. Chem., 2015, 13, 9445-9456.

83 T. Takeuchi, V. Bagnacani, F. Sansone and S. Matile, ChemBioChem, 2009, 10, 2793-2799.

84 E. Bartolami, Y. Bessin, V. Gervais, P. Dumy and S. Ulrich, Angew. Chem., Int. Ed., 2015, 54, 10183-10187.

85 E. Bartolami, Y. Bessin, N. Bettache, M. Gary-Bobo, M. Garcia, P. Dumy and S. Ulrich, Org. Biomol. Chem., 2015, 13, 9427-9438.

86 R. V. Benjaminsen, M. A. Mattebjerg, J. R. Henriksen, S. M. Moghimi and T. L. Andresen, Mol. Ther., 2013, 21, 149157.

87 E. Vuorimaa-Laukkanen, E. S. Lisitsyna, T.-M. Ketola, E. Morin-Pickardat, H. M. Liang, M. Hanzlíková and M. Yliperttula, Eur. J. Pharm. Sci., 2017, 103, 122-127.

88 A. v. Harpe, H. Petersen, Y. X. Li and T. Kissel, J. Control Release, 2000, 69, 309-322.

89 A. Schroeder, J. E. Dahlman, G. Sahay, K. T. Love, S. Jiang, A. A. Eltoukhy, C. G. Levins, Y. X. Wang and D. G. Anderson, J. Control Release, 2012, 160, 172-176.

90 C. H. Li, D. G. Zhong, Y. Zhang, W. W. Tuo, N. Li, Q. Wang, Z. H. Liu and W. Xue, J. Mater. Chem. B, 2013, 1, 18851893.

91 Z. Y. Wu, S. Y. Zhan, W. Fan, X. Y. Ding, X. Wu, W. Zhang, Y. H. Fu, Y. Y. Huang, X. Huang, R. B. Chen, M. J. Li, N. Y. Xu, Y. X. Zheng and B. Y. Ding, Nanoscale Res. Lett., 2016, 11, 122.

92 B. F. Craciun, G. Gavril, D. Peptanariu, L. E. Ursu, L. Clima and M. Pinteala, Molecules, 2019, 24, 1460.

93 C. L. Yu, E. Tan, Y. Y. Xu, J. Lv and Y. Y. Cheng, Bioconj. Chem., 2019, 30, 413-417.
94 N. J. Treat, D. D. Smith, C. W. Teng, J. D. Flores, B. A. Abel, A. W. York, F. Q. Huang and C. L. McCormick, ACS Macro Lett., 2012, 1, 100-104.

95 C.-Y. Sun, S. Shen, C.-F. Xu, H.-J. Li, Y. Liu, Z.-T. Cao, X.-Z. Yang, J.-X. Xia and J. Wang, J. Am. Chem. Soc., 2015, 137, 15217-15224.

96 G. Gasparini, E.-K. Bang, J. Montenegro and S. Matile, Chem. Commun., 2015, 51, 10389-10402.

97 M. Nishihara, F. Perret, T. Takeuchi, S. Futaki, A. N. Lazar, A. W. Coleman, N. Sakai and S. Matile, Org. Biomol. Chem., 2005, 3, 1659-1669.

98 Y. Maitani and Y. Hattori, Expert Opin. Drug Deliv., 2009, 6, 1065-1077.

99 S. Junghänel, S. Karczewski, S. Bäcker, S. K. Knauer and C. Schmuck, ChemBioChem, 2017, 18, 2268-2279.

100 M. Giese, J. Niemeyer and J. Voskuhl, Chempluschem, 2020, 85, 985-997.

101 J. Hatai and C. Schmuck, Acc. Chem. Res., 2019, 52, 17091720.

102 P. Midoux and M. Monsigny, Bioconj. Chem., 1999, 10, 406-411.

103 J. Shi, J. G. Schellinger, R. N. Johnson, J. L. Choi, B. Chou, E. L. Anghel and S. H. Pun, Biomacromolecules, 2013, 14, 1961-1970.

104 H. S. Hwang, J. Hu, K. Na and Y. H. Bae, Biomacromolecules, 2014, 15, 3577-3586.

105 E. Bertrand, C. Goncalves, L. Billiet, J. P. Gomez, C. Pichon, H. Cheradame, P. Midoux and P. Guegan, Chem. Commun., 2011, 47, 12547-12549.

106 R. Szabó, M. Sebestyén, G. Kóczán, Á. Orosz, G. Mező and F. Hudecz, ACS Comb. Sci., 2017, 19, 246-254.

107 H. T. Lv, S. B. Zhang, B. Wang, S. H. Cui and J. Yan, J. Control Release, 2006, 114, 100-109.

108 H. S. Hwang, H. C. Kang and Y. H. Bae, Biomacromolecules, 2013, 14, 548-556.

109 N. J. van Zee and R. Nicolaÿ, Prog. Polym. Sci., 2020, 101233.

110 P. Chakma and D. Konkolewicz, Angew. Chem., Int. Ed., 2019, 58, 9682-9695.

111 C. Xu, X. W. Guan, L. Lin, Q. Wang, B. Gao, S. H. Zhang, Y. H. Li and H. Y. Tian, ACS Biomater. Sci. Eng., 2018, 4, 193199.

112 M. E. Bracchi, G. Dura and D. A. Fulton, Polym. Chem., 2019, 10, 1258-1267.

113 A. Vaish and N. V. Tsarevsky, Polym. Chem., 2019, 10, 3943-3950.

114 C. Dohmen, D. Edinger, T. Fröhlich, L. Schreiner, U. Lächelt, C. Troiber, J. Rädler, P. Hadwiger, H.-P. Vornlocher and E. Wagner, ACS Nano, 2012, 6, 5198-5208.

115 Y. H. Jin, Q. Wang, P. Taynton and W. Zhang, Acc. Chem. Res., 2014, 47, 1575-1586.

116 D. Abegg, G. Gasparini, D. G. Hoch, A. Shuster, E. Bartolami, S. Matile and A. Adibekian, J. Am. Chem. Soc., 2017, 139, 231-238.

117 S. Ulrich, D. Boturyn, A. Marra, O. Renaudet and P. Dumy, Chem. - Eur. J., 2014, 20, 34-41. 
118 D. K. Kölmel and Eric T. Kool, Chem. Rev., 2017, 117, 10358-10376.

119 M. E. Belowich and J. F. Stoddart, Chem. Soc. Rev., 2012, 41, 2003-2024.

120 J. Kalia and R. T. Raines, Angew. Chem., Int. Ed., 2008, 47, 7523-7526.

121 S. Cambray and J. Gao, Acc. Chem. Res., 2018, 51, 21982206.

122 A. Bandyopadhyay and J. M. Gao, Chem. - Eur. J., 2015, 21, 14748-14752.

123 E. T. Kool, P. Crisalli and K. M. Chan, Org. Lett., 2014, 16, 1454-1457.

124 E. T. Kool, D. H. Park and P. Crisalli, J. Am. Chem. Soc., 2013, 135, 17663-17666.

125 D. Larsen, A. M. Kietrys, S. A. Clark, H. S. Park, A. Ekebergh and E. T. Kool, Chem. Sci., 2018, 9, 5252-5259.

126 A. Dirksen, S. Dirksen, T. M. Hackeng and P. E. Dawson, J. Am. Chem. Soc., 2006, 128, 15602-15603.

127 A. Dirksen, T. M. Hackeng and P. E. Dawson, Angew. Chem., Int. Ed., 2006, 45, 7581-7584.

128 A. Dirksen and P. E. Dawson, Bioconj. Chem., 2008, 19, 2543-2548.

129 P. Crisalli and E. T. Kool, Org. Lett., 2013, 15, 1646-1649.

130 P. Crisalli and E. T. Kool, J. Org. Chem., 2013, 78, 11841189.

131 M. N. Chaur, D. Collado and J.-M. Lehn, Chem. - Eur. J., 2011, 17, 248-258.

132 D. J. van Dijken, P. Kovaricek, S. P. Ihrig and S. Hecht, J. Am. Chem. Soc., 2015, 137, 14982-14991.

133 Z. L. Pianowski, J. Karcher and K. Schneider, Chem. Commun., 2016, 52, 3143-3146.

134 P. A. Fernandes and M. J. Ramos, Chem. - Eur. J., 2004, 10, 257-266.

135 S. P. Black, J. K. M. Sanders and A. R. Stefankiewicz, Chem. Soc. Rev., 2014, 43, 1861-1872.

136 S. Bauhuber, C. Hozsa, M. Breunig and A. Göpferich, Adv. Mater., 2009, 21, 3286-3306.

137 G. David, L. Clima, M. Calin, C. A. Constantinescu, M. Balan-Porcarasu, C. M. Uritu and B. C. Simionescu, Polym. Chem., 2018, 9, 1072-1081.

138 S. Liu, Y. S. Gao, D. Z. Zhou, M. Zeng, F. Alshehri, B. Newland, J. Lyu, J. O'Keeffe-Ahern, U. Greiser, T. Y. Guo, F. Z. Zhang and W. X. Wang, Nat. Commun., 2019, 10, 3307.

139 D. C. Zhu, H. J. Yan, X. Liu, J. J. Xiang, Z. X. Zhou, J. B. Tang, X. R. Liu and Y. Q. Shen, Adv. Funct. Mater., 2017, 27, 1606826.

140 H. J. Zhu, J. An, C. C. Pang, S. Chen, W. Li, J. B. Liu, Q. X. Chen and H. Gao, J. Mater. Chem. B, 2019, 7, 384-392.

141 F. Sansone, M. Dudic, G. Donofrio, C. Rivetti, L. Baldini, A. Casnati, S. Cellai and R. Ungaro, J. Am. Chem. Soc., 2006, 128, 14528-14536.

142 T. Takeuchi, J. Montenegro, A. Hennig and S. Matile, Chem. Sci., 2011, 2, 303-307.

143 A. Verma and F. Stellacci, Small, 2010, 6, 12-21.

144 A. Aissaoui, B. Martin, E. Kan, N. Oudrhiri, M. Hauchecorne, J.-P. Vigneron, J.-M. Lehn and P. Lehn, J. Med. Chem., 2004, 47, 5210-5223.
145 N. Oudrhiri, J.-P. Vigneron, M. Peuchmaur, T. Leclerc, J.-M. Lehn and P. Lehn, Proc. Natl. Acad. Sci., 1997, 94, 16511656.

146 J. Montenegro, A. Fin and S. Matile, Org. Biomol. Chem., 2011, 9, 2641-2647.

147 J. Montenegro, P. Bonvin, T. Takeuchi and S. Matile, Chem. - Eur. J., 2010, 16, 14159-14166.

148 S. M. Butterfield, T. Miyatake and S. Matile, Angew. Chem., Int. Ed., 2009, 48, 325-328.

149 T. Takeuchi and S. Matile, J. Am. Chem. Soc., 2009, 131, 18048-18049.

150 C. Gehin, J. Montenegro, E.-K. Bang, A. Cajaraville, S. Takayama, H. Hirose, S. Futaki, S. Matile and H. Riezman, J. Am. Chem. Soc., 2013, 135, 9295-9298.

151 E.-K. Bang, G. Gasparini, G. Molinard, A. Roux, N. Sakai and S. Matile, J. Am. Chem. Soc., 2013, 135, 2088-2091.

152 D. Oupický, A. L. Parker and L. W. Seymour, J. Am. Chem. Soc., 2002, 124, 8-9.

153 W. Yang, C. Yu, C. Wu, S. Q. Yao and S. Wu, Polym. Chem. 2017, 8, 4043-4051.

154 N. Chuard, G. Gasparini, A. Roux, N. Sakai and S. Matile, Org. Biomol. Chem., 2015, 13, 64-67.

155 G. Gasparini, E.-K. Bang, G. Molinard, D. V. Tulumello, S. Ward, S. O. Kelley, A. Roux, N. Sakai and S. Matile, J. Am. Chem. Soc., 2014, 136, 6069-6074.

156 L.-L. Zong, E. Bartolami, D. Abegg, A. Adibekian, N. Sakai and S. Matile, ACS Cent. Sci., 2017, 3, 449-453.

157 G. Gasparini, G. Sargsyan, E.-K. Bang, N. Sakai and S. Matile, Angew. Chem., Int. Ed., 2015, 54, 7328-7331.

158 G. S. Pulcu, N. S. Galenkamp, Y. Qing, G. Gasparini, E. Mikhailova, S. Matile and H. Bayley, J. Am. Chem. Soc., 2019, 141, 12444-12447.

159 P. Morelli, E. Bartolami, N. Sakai and S. Matile, Helv. Chim. Acta, 2018, 101

160 X. Liao, G. Walden, N. D. Falcon, S. Donell, M. J. Raxworthy, M. Wormstone, G. P. Riley and A. Saeed, Eur. Polym. J., 2017, 87, 458-467.

161 C. Bouillon, Y. Bessin, F. Poncet, M. Gary-Bobo, P. Dumy, M. Barboiu, N. Bettache and S. Ulrich, J. Mater. Chem. B, 2018, 6, 7239-7246.

162 J. M. Priegue, D. N. Crisan, J. Martínez-Costas, J. R. Granja, F. Fernandez-Trillo and J. Montenegro, Angew. Chem., Int. Ed., 2016, 55, 7492-7495.

163 I. Louzao, R. García-Fandiño and J. Montenegro, J. Mater. Chem. B, 2017, 5, 4426-4434.

164 C. S. Mahon and D. A. Fulton, Chem. Sci., 2013, 4, 36613666.

165 C. S. Mahon and D. A. Fulton, Nat. Chem., 2014, 6, 665672.

166 C. S. Mahon, A. W. Jackson, B. S. Murray and D. A. Fulton, Chem. Commun., 2011, 47, 7209-7211.

167 M. Juanes, O. Creese, P. Fernandez-Trillo and J. Montenegro, Med. Chem. Commun., 2019, 10, 1138-1144.

168 J. M. Priegue, I. Lostalé-Seijo, D. Crisan, J. R. Granja, F. Fernández-Trillo and J. Montenegro, Biomacromolecules, 2018, 19, 2638-2649. 
169 A. Fuertes, M. Juanes, J. R. Granja and J. Montenegro, Chem. Commun., 2017, 53, 7861-7871.

170 I. Gallego, A. Rioboo, J. J. Reina, B. Diaz, A. Canales, F. J. Canada, J. Guerra-Varela, L. Sanchez and J. Montenegro, ChemBioChem, 2019, 20, 1400-1409.

171 D. L. McKenzie, E. Smiley, K. Y. Kwok and K. G. Rice, Bioconj. Chem., 2000, 11, 901-909.

172 T. Blessing, J.-S. Remy and J.-P. Behr, Proc. Natl. Acad. Sci., 1998, 95, 1427-1431.

173 D. L. McKenzie, K. Y. Kwok and K. G. Rice, J. Biol. Chem., 2000, 275, 9970-9977.

174 R. Catana, M. Barboiu, I. Moleavin, L. Clima, A. Rotaru, E.L. Ursu and M. Pinteala, Chem. Commun., 2015, 51, 20212024.

175 D. Ailincai, D. Peptanariu, M. Pinteala and L. Marin, Mater. Sci. Eng. C Mater. Biol. Appl., 2019, 94, 635-646.

176 L. Clima, B. F. Craciun, G. Gavril and M. Pinteala, Polymers, 2019, 11, 1313.

177 I.-A. Turin-Moleavin, F. Doroftei, A. Coroaba, D. Peptanariu, M. Pinteala, A. Salic and M. Barboiu, Org. Biomol. Chem., 2015, 13, 9005-9011.

178 L. Marin, D. Ailincai, M. Calin, D. Stan, C. A. Constantinescu, L. Ursu, F. Doroftei, M. Pinteala, B. C. Simionescu and M. Barboiu, ACS Biomater. Sci. Eng., 2016, 2, 104-111.

179 L. Clima, D. Peptanariu, M. Pinteala, A. Salic and M. Barboiu, Chem. Commun., 2015, 51, 17529-17531.

180 P. C. Gareiss and B. L. Miller, in Dynamic Combinatorial Chemistry In Drug Discovery, Bioorganic Chemistry, and Materials Science, ed. B. L. Miller, John Wiley \& Sons, Inc., 2010.

181 P. K. Hashim, K. Okuro, S. Sasaki, Y. Hoashi and T. Aida, J. Am. Chem. Soc., 2015, 137, 15608-15611.

182 A. Kohata, P. K. Hashim, K. Okuro and T. Aida, J. Am. Chem. Soc., 2019, 141, 2862-2866.

183 L. Shen, Y. Li, Q. Lu, X. Qi, X. Wu, Z. Zhou and J. Shen, Chem. Commun., 2020, 56, 2411-2414.

184 B. Bechinger, Cell. Mol. Life Sci., 2008, 65, 3028-3039.

185 C. Bechara and S. Sagan, FEBS Lett., 2013, 587, 1693-1702.

186 V. Saggiomo, C. Goeschen, R. Herges, R. Quesada and U. Luning, Eur. J. Org. Chem., 2010, 2010, 2337-2343.

187 V. Saggiomo and U. Luning, Chem. Commun., 2009, 37113713.

188 X. Wu, N. Busschaert, N. J. Wells, Y. B. Jiang and P. A. Gale, J. Am. Chem. Soc., 2015, 137, 1476-1484.

189 G. Nasr, T. Macron, A. Gilles, E. Petit and M. Barboiu, Chem. Commun., 2012, 48, 7398-7400.

190 A. Cazacu, Y. M. Legrand, A. Pasc, G. Nasr, A. van der Lee, E. Mahon and M. Barboiu, Proc. Natl. Acad. Sci., 2009, 106, 8117-8122.

191 G. Lattig-Tunnemann, M. Prinz, D. Hoffmann, J. Behlke, C. Palm-Apergi, I. Morano, H. D. Herce and M. C. Cardoso, Nat. Commun., 2011, 2, 453.

192 M. A. Cortez, W. T. Godbey, Y. L. Fang, M. E. Payne, B. J. Cafferty, K. A. Kosakowska and S. M. Grayson, J. Am. Chem. Soc., 2015, 137, 6541-6549.
193 S. Aubry, F. Burlina, E. Dupont, D. Delaroche, A. Joliot, S. Lavielle, G. Chassaing and S. Sagan, FASEB J., 2009, 23, 2956-2967.

194 N. Chuard, A. I. Poblador-Bahamonde, L. L. Zong, E. Bartolami, J. Hildebrandt, W. Weigand, N. Sakai and S. Matile, Chem. Sci., 2018, 9, 1860-1866.

195 Y. Cheng, L. Zong, J. López-Andarias, E. Bartolami, Y. Okamoto, T. R. Ward, N. Sakai and S. Matile, Angew. Chem., Int. Ed., 2019, 58, 9522-9526.

196 E. Bartolami, D. Basagiannis, L. L. Zong, R. Martinent, Y. Okamoto, Q. Laurent, T. R. Ward, M. Gonzalez-Gaitan, N. Sakai and S. Matile, Chem. - Eur. J., 2019, 25, 4047-4051.

197 N. Chuard, G. Gasparini, D. Moreau, S. Lorcher, C. Palivan, W. Meier, N. Sakai and S. Matile, Angew. Chem., Int. Ed., 2017, 56, 2947-2950.

198 Y. Y. Cheng, L. L. Zong, J. Lopez-Andarias, E. Bartolami, Y. Okamoto, T. R. Ward, N. Sakai and S. Matile, Angew. Chem., Int. Ed., 2019, 58, 9522-9526.

199 T. Li, W. Gao, J. J. Liang, M. R. Zha, Y. Q. Chen, Y. B. Zhao and C. L. Wu, Anal. Chem., 2017, 89, 8501-8508.

200 X. T. Meng, T. Li, Y. B. Zhao and C. L. Wu, ACS Chem. Biol., 2018, 13, 3078-3086.

201 E. Mahon and M. Barboiu, Org. Biomol. Chem., 2015, 13, 10590-10599.

202 M. J. Chmielewski, E. Buhler, J. Candau and J. M. Lehn, Chem. - Eur. J., 2014, 20, 6960-6977.

203 K. Petkau-Milroy and L. Brunsveld, Eur. J. Org. Chem., 2013, 3470-3476. 